\title{
Detection and Characterization of Ignitable Liquid Residues in Forensic Fire Debris Samples by Comprehensive Two-Dimensional Gas Chromatography
}

\author{
Andjoe A. S. Sampat ${ }^{1, *}$, Brenda van Daelen ${ }^{1}$, Martin Lopatka ${ }^{2,3}$, Hans Mol ${ }^{4}$, \\ Guido van der Weg ${ }^{4}$, Gabriel Vivó-Truyols ${ }^{1}$, Marjan Sjerps ${ }^{2,3}$, Peter J. Schoenmakers ${ }^{1}$ \\ and Arian C. van Asten 1,2,5 \\ 1 van't Hoff Institute for Molecular Sciences, Faculty of Science, University of Amsterdam, P.O. Box 94157, \\ 1090 GD Amsterdam, The Netherlands; brenda.van.daealen@gmail.com (B.v.D.); \\ g.vivotruyols@tecnometrix.com (G.V.-T.); p.j.schoenmakers@uva.nl (P.J.S.); \\ a.van.asten@nfi.minvenj.nl (A.C.v.A.) \\ 2 Netherlands Forensic Institute, P.O. Box 24044, 2490 AA The Hague, The Netherlands; \\ martin.lopatka@gmail.com (M.L.); m.sjerps@nfi.minvenj.nl (M.S.) \\ 3 Korteweg-de Vries Institute for Mathematics, Faculty of Science, University of Amsterdam, P.O. Box 94248, \\ 1090 GE Amsterdam, The Netherlands \\ 4 RIKILT-Institute of Food Safety, Wageningen University, P.O. Box 230, 6700 AE Wageningen, \\ The Netherlands; hans.mol@wur.nl (H.M.); guido.vanderweg@wur.nl (G.v.d.W.) \\ 5 Co van Ledden Hulsebosch Center (CLHC), Amsterdam Center for Forensic Science and Medicine, \\ P.O. Box 94157, 1090 GD Amsterdam, The Netherlands \\ * Correspondence: andjoe.sampat@gmail.com
}

Received: 29 July 2018; Accepted: 20 August 2018; Published: 27 August 2018

\begin{abstract}
This study covers an extensive experimental design that was developed for creating simulated fire debris samples under controlled conditions for the detection and identification of ignitable liquids (IL) residues. This design included 19 different substrates, 45 substrate combinations with and without ignitable liquids, and 45 different ILs from three classes (i.e., white spirit, gasoline, and lamp oil). Chemical analysis was performed with comprehensive two-dimensional gas chromatography coupled to time-of-flight mass spectrometry (GC $\times$ GC-TOFMS) for improved separation and compound identification. The enhanced peak capacity offered by GC $\times$ GC-TOFMS allowed the use of a target compound list in combination with a simple binary decision model to arrive at quite acceptable results with respect to IL detection ( $89 \%$ true positive and $7 \%$ false positive rate) and classification (100\% correct white spirit, $79 \%$ correct gasoline, and $77 \%$ correct lamp oil assignment). Although these results were obtained in a limited set of laboratory controlled fire experiments including only three IL classes, this study confirms the conclusions of other studies that $\mathrm{GC} \times \mathrm{GC}-\mathrm{TOFMS}$ can be a powerful tool in the challenging task of forensic fire debris analysis.
\end{abstract}

Keywords: Comprehensive two-dimensional gas chromatography; GC $\times$ GC; GC $\times$ GC-TOFMS; fire debris analysis; ignitable liquids; arson; forensic fire investigation; medium petroleum distillate; simulated fire debris samples

\section{Introduction}

Fire debris analysis is performed for the identification and/or classification of ignitable liquid residues (ILRs) in samples taken from a post fire incident scene. The presence of such residues can be indicative of arson as opposed to an accidental fire. These type of analyses were carried out as early 
as 1911 [1] and have developed throughout the years alongside improved technologies for chemical analysis. Currently, gas chromatography with mass spectrometry (GC-MS) is the most common analytical technique to be used for fire debris analysis in line with ASTM (American Society for Testing and Materials) standards [2]. Although the current methodology is adequate, many institutes and research facilities invest in improving the analytical approaches and sampling techniques in order to enhance the added value of forensic fire investigation. A couple of comprehensive reviews were published covering the development on fire debris analysis with respect to the analytical techniques and tools, sample preparation, and data treatment during the past 15 years [3-5].

Fire debris analysis is a complex and challenging task due to several interfering factors, such as (i) substrate variability and released pyrolysis products that are also commonly found in ignitable liquids (IL); (ii) the complex chemical composition of different types of ignitable liquid; (iii) evaporation and consumption of the ignitable liquid during a fire; and (iv) (bio)-degradation of fire debris samples. Several studies have been conducted based on classification and within-class differentiation with the use of neat ignitable liquids in order to improve the detection and classification of ILRs in fire debris samples [6-9]. An overview of challenges in terms of the variety of ignitable liquids, classification and matrix interferences in fire debris analysis has been provided by Baerncopf et al. [10]. Due to the complexity of the samples, matrix interferences, the variety of ignitable liquids, and variation within a class of ILs [6], fully automated data treatment and analysis is often not feasible and the results have to be subjectively interpreted by a forensic expert in the field. Proficiency tests have shown that difficult cases are prone to erroneous expert interpretation [11]. Controlled fire simulations might give a better understanding and improve methodology. Although actual fires are uncontrolled and erratic in nature, small scale fire simulations can allow a more systematic study as key parameters are known and controlled. It is however important that these parameters match realistic fire conditions to ensure that the experimental work has forensic relevance. To the best of our knowledge only a limited number of scientific studies describing the use of simulated fire debris samples have appeared in scientific literature.

Prather et al. [12] investigated the weathering process by extracting ILRs from simulated fire debris samples and comparing the residues to the corresponding neat IL. Small pieces $(4 \mathrm{~cm} \times 4 \mathrm{~cm})$ of carpet material were spiked with aliquots of gasoline and kerosene and subsequently burned for $60 \mathrm{~s}$. The fire debris samples were extracted using activated carbon strips and eluted with $200 \mu \mathrm{L}$ dichloromethane (DCM). A combination of multivariate statistical procedures (i.e., mean Pearson product moment correlation (PPMC), hierarchical clustering analysis (HCA), and principal component analysis (PCA)) were applied. With PPMC strong correlations were calculated for both the gasoline and kerosene for the different evaporation levels. As expected, weak correlations were obtained when comparing gasoline and kerosene. Although HCA and PPMC were found to be good statistical methods to establish sample similarity, PCA yielded the best reduction of matrix interferences.

The complexity of fire debris analysis is also the result of the presence of interfering products, which can be divided into volatile products from the substrate as such (unburned, i.e., already present) and the released pyrolysis and combustion products (burned, i.e., formed and released) $[1,13]$. The chemical profile of these released compounds can be similar to that of ignitable liquids. Forensic scientists therefore always have to be alert not to consider interfering products as distinctive markers for certain ILs [13]. Fernandes et al. [14] investigated the release of interfering products for common household products. Therefore, a wide variety of products were obtained such as magazines, different floorcoverings, and building materials. Passive headspace adsorption was used to detect released volatile compounds before and after burning of the materials. From the results it became clear that the volatile compounds originating from the material itself (substrate background products) could form an obstacle in fire debris analysis and interpretation. Magazines for example showed a diesel-like profile before and after burning, and could therefore easily lead to a false positive outcome. The presence of interfering components from carpet was also discussed by Li et al. [15]. Two pieces of carpet were burned with and without the addition of gasoline and subjected to GC-MS analysis. Intact gasoline was 
also analyzed and 38 compounds were listed as target compounds. Some of these target compounds were also found to be combustion and pyrolysis products emanating from the burned carpets.

A detailed study was conducted by Borusiewicz et al. [16] on potential fire debris. In this research the effect of (i) various substrate materials; (ii) different burning times; (iii) type of ignitable liquids; and (iv) air supply during burning on the detection and identification of ILRs in fire debris analysis was investigated. Experiments were carried out in small open containers. Three types of materials were used, i.e., wood logs $(30 \mathrm{~cm}$ long), carpet $(20 \mathrm{~cm} \times 15 \mathrm{~cm})$, and chipboard $(10 \mathrm{~cm} \times 20 \mathrm{~cm} \times 1.2 \mathrm{~cm})$ and five ILs, i.e., gasoline, kerosene, diesel, a solvent, and a diluter. After applying $250 \mathrm{~cm}^{3}$ of IL on the substrate materials the samples were ignited and left to burn initially with burning times in the range of 20 to $80 \mathrm{~min}$ and later on a fixed burning time of 50, 60, and $70 \mathrm{~min}$. Samples were collected in air-tight glass jars. Headspace samples were analyzed with GC-MS. Of the tested parameters the analysis was affected the most by the type of material used in the burn experiment.

Almirall et al. [17] conducted an extensive study to identify target compounds of controlled burns of materials normally found in houses and office areas, such as floorcoverings, wallpaper, plastics, packaging materials, magazines, and clothing. In total, 35 samples were analyzed with GC-MS preand post-fire. Burn experiments were performed by placing some of the substrate material in a paint can and subsequently burning the material for $2 \mathrm{~min}$ or at least until only $1 / 3$ of the material was intact. Controlled pyrolysis experiments were also performed for a total of 23 substrates using a pyrolyzer coupled to the GC-MS system. Headspace analysis was carried out and pretreated according to ASTM 1412-00 using carbon strips [18]. In another study, Lennard et al. [19] described the development of a target compound chromatogram (TCC) method in which peak areas were collected, normalized, and stored in a database. The presence and identity of a possible accelerant could be confirmed with this method by automatically searching the unknown accelerants against the TCC in the database that consisted of standard samples. Samples that were used in this study consisted of several hydrocarbons and were analyzed as such, after weathering or after controlled burn experiments on different substrate materials. Simulated fire debris samples were also used in the study of Schwartz and coworkers [20] in an attempt to test whether it is possible to predict the IL used in a fire debris sample through compound-specific isotope analysis. Samples were prepared by submerging carpet material into a beaker with ignitable liquid. Excess liquid was drained and the carpet was placed in a Pyrex beaker, followed by the burning procedure with a Bunsen burner until it self-extinguished. Subsequently, $2 \mathrm{~cm} \times 2 \mathrm{~cm}$ pieces of burnt carpet were cut, extracted with hexane, and placed in vials for analysis. However, although compound-specific isotopic analyzer could be used to differentiate between various sources of ILs, this approach proved to be unsuitable for application in fire debris analysis.

Choi et al. [21] used a different approach based on laser induced breakdown spectroscopy to determine the ignition source and the possible presence of an accelerant in fire debris samples. For this study five types of substrates were used, i.e., electrical wires, two different floor materials, mats, and a sheet. These materials were burnt with and without an IL. As an accelerant a hydrocarbon based liquid was used. Three types of ignition sources were investigated, e.g., a candle, a gas stove, and a lighter. With the use of depth profiling it was possible to determine the source of ignition. The presence of an IL was confirmed by looking at the thickness of the carbon layer formed and the extensive burn damage on the surface. A thick carbon layer confirms the presence of an IL, while when using no IL a thin carbon layer was formed.

As is illustrated to date, only a handful of studies have been carried out to optimize the detection and identification of ignitable liquids in fire debris on the basis of simulated fire debris samples.

In this study we present an experimental design for laboratory-scale controlled fire experiments, which was earlier introduced by Lopatka et al. [22]. The design combines high-throughput, controlled testing, complete sample collection, and realistic burn conditions with respect to substrate composition, IL/substrate ratio, and burn time (see Sections 2.2 and 2.3). A large series of controlled laboratory-scale fire debris samples were prepared for the detection and identification of ILRs. Chemical analysis was performed with comprehensive two-dimensional gas chromatography coupled to time-of-flight mass 
spectrometry (GC $\times$ GC-TOFMS) for enhanced separation and compound identification. This analytical technique is still emerging in the forensic field $[23,24]$, but not frequently used in forensic fire investigations $[8,22,25-28]$. A variety of substrates was used to reflect the complexity of real fire debris samples. An experimental design was applied consisting of various substrates commonly found in regular households. Three different classes of ignitable liquids (i.e., gasoline, white spirit, and lamp oil) were used. Of each class, 15 different batches/bottles of ILs were purchased from various locations/stores in the Netherlands. Fire headspace analysis was performed for 19 single substrates and 45 different combinations of five of these substrates. These substrate combinations were set on fire without the addition of IL and after the addition of in total 45 different intact ILs (15 ILs for each product class). The obtained GC $\times$ GC-TOFMS dataset was used in previous studies wherein chemometric techniques for data reduction and feature selection were applied for the detection and classification of ILRs in fire debris samples [22,26]. To our knowledge this is the first study combining lab scale fire experiments under realistic conditions with the comprehensive two-dimensional gas chromatographic $(\mathrm{GC} \times \mathrm{GC}$ and GC $\times$ GC-TOFMS) analysis on the resulting fire debris samples using a simple chemistry based approach to deal with complex GC $\times$ GC data.

\section{Materials and Methods}

\subsection{Chemicals and Samples}

Substrates used for the burn experiments are listed in Table 1. Three types of ignitable liquids used were white spirit, lamp oil, and gasoline (for details see Table S1). Of each type, 15 samples were obtained to perform the burn experiments. Dichloromethane stabilized with Amylene (DCM, assay min. 99.9\%; Biosolve, Valkenswaard, The Netherlands) was used to desorb the trapped compounds from the charcoal adsorption tubes. DCM was spiked with chlorobenzene (Chem Service, Alltech, Dieren, The Netherlands) as internal standard (IS) at a concentration of $0.01 \mathrm{mg} / \mathrm{mL}$. Neat ignitable liquids were also analyzed by dilution with spiked DCM to a final concentration of $0.01 \mathrm{mg} / \mathrm{mL}$. A performance test solution was used for quality control and for monitoring retention-time shifts. It contained the following aliphatic and aromatic compounds at a concentration of $0.005 \mathrm{mg} / \mathrm{mL}$ each (Zwijndrecht, The Netherlands), 1-ethyl-2-methylbenzene (Chem Service, Alltech, Dieren, The Netherlands), $n$-nonane and $n$-decane (Acros Organics, Geel, Belgium), $n$-undecane (Merck, Darmstadt, Germany), n-dodecane, and $n$-tridecane (Acros Organics, Geel, Belgium). 
Table 1. List of substrates used in the burn experiments. Most of the materials were obtained second hand through personal contacts (e.g., left-over floor skirting) and the same batch of material was used throughout, except for curtain material (two batches). Items in italic script were not used as primary substrate in the experimental design.

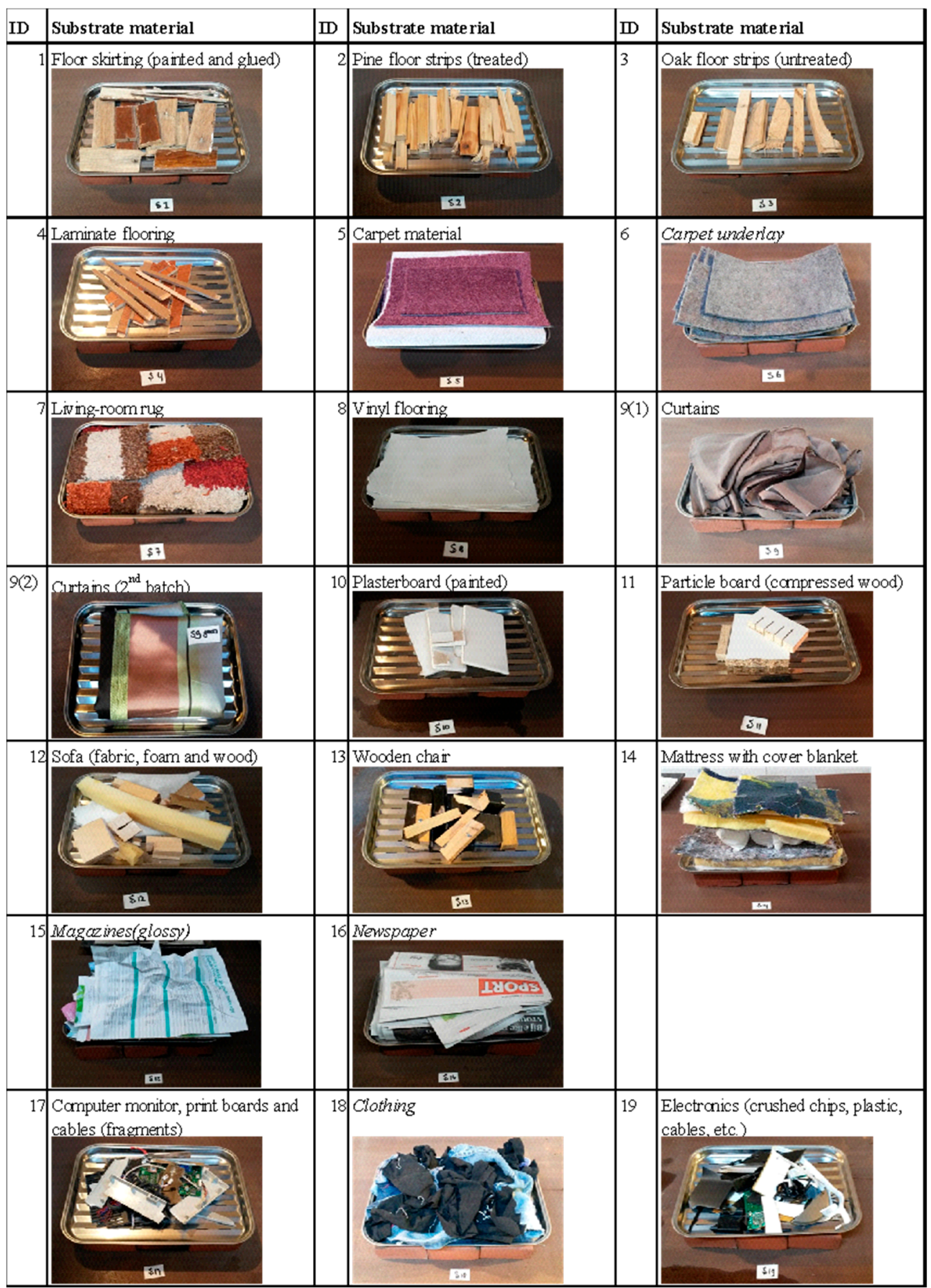

\subsection{Preparation of Laboratory-Scale Fire Debris Samples}

Laboratory-scale fire debris samples of various substrate combinations were conducted on the basis of an experimental design (Table 2) that consisted of a total of 155 experiments. Nineteen different substrates were used (see Table 1) including furniture and building materials commonly found in homes. Individual materials were chosen that are frequently encountered in residential fire investigations on the basis of fire debris literature and casework. In actual casework the collected fire 
debris is often a combination of different types of substrates. To simulate reality, various combinations of different substrates were used in this study. For each experiment one primary substrate was chosen (accounting for 60 weight percentage ( $w \mathrm{t} \%$ ) of the total mass of materials), and this was combined with four so-called secondary substrates contributing to the remaining $40 \mathrm{wt} \%$ of the sample. Not all nineteen substrates were selected as primary substrate, depending on the expected abundance in regular households. Carpet underlay, clothing, magazines, and paper were not used as primary substrates, resulting in 15 suitable primary substrates. Each of the primary substrates (See Table 1) were subjected to each type of IL (i.e., gasoline, white spirit, and lamp oil) in combination with four variable secondary substrates.

The design of experiments included substrate mixtures prepared in duplicate and were burned both with and without the addition of ignitable liquids. This was intended to facilitate an investigation of the detectable chemical markers contributed by ILR in the sample and facilitate research into the detection of ILR with diverse substrate and IL samples. This resulted in 45 burn experiments without IL and 45 experiments with IL. In order to further explore the analytical data in detail, the 19 individual substrate materials were each burned separately. Additionally, the 45 intact ILs were analyzed separately to explore which IL constituents can potentially act as marker compounds for IL presence and whether ILs in a given class could be differentiated even as residues in a fire debris sample.

In general, the experimental design allows for several levels of forensic hypotheses to be examined. The detection of ILR in a diversity of realistic substrate mixtures can be explored, as well as the classification of ILR into chemically distinct types. Also of interest is the identification of chemical markers in performing discrimination and characterization tasks.

Table 2. Overview of all conducted burn experiments. Primary substrates constituted $60 \%$ by weight. Secondary materials constituted $10 \%$ each. Substrate numbers refer to Table 1 . Two different pieces of curtain were used in this study, indicated in bracketed numbers for experiments that included one of these batches. Detailed information about the bottles/batches of IL can be found in Table S1.

\begin{tabular}{|c|c|c|c|c|c|c|}
\hline \multicolumn{2}{|c|}{$\begin{array}{l}\text { Single Substrate } \\
\text { Material Burns }\end{array}$} & \multicolumn{3}{|c|}{ Substrate Mixture Material Burns } & \multicolumn{2}{|c|}{ Substrate Mixture Material Burns with IL } \\
\hline Exp \# & Substrate & Exp \# & $\begin{array}{l}\text { Primary } \\
\text { Substrate }\end{array}$ & Secondary Substrates & Exp \# & Substrate + IL \\
\hline 1 & 1 & 20 & 1 & $10 \quad 12 \quad 16$ & 65 & Same as \#020 + IL 1 Bottle 1 \\
\hline 2 & 2 & 21 & 2 & $\begin{array}{llll}7 & 10 & 17 & 19\end{array}$ & 66 & Same as \#021 + IL 1 Bottle 2 \\
\hline 3 & 3 & 22 & 3 & $\begin{array}{llll}12 & 7 & 15 & 17\end{array}$ & 67 & Same as \#022 + IL 1 Bottle 3 \\
\hline 4 & 4 & 23 & 4 & $\begin{array}{llll}10 & 13 & 16 & 18\end{array}$ & 68 & Same as \#023 + IL 1 Bottle 4 \\
\hline 5 & 5 & 24 & 5 & $\begin{array}{llll}3 & 6 & 17 & 19\end{array}$ & 69 & Same as \#024 + IL 1 Bottle 5 \\
\hline 6 & 6 & 25 & 7 & $\begin{array}{llll}2 & 4 & 6 & 10\end{array}$ & 70 & Same as \#025 + IL 1 Bottle 6 \\
\hline 7 & 7 & 26 & 8 & $9(1) \quad 13 \quad 15 \quad 18$ & 71 & Same as \#026 + IL 1 Bottle 7 \\
\hline 8 & 8 & 27 & 9(1) & $\begin{array}{llll}4 & 16 & 12 & 18\end{array}$ & 72 & Same as \#027 + IL 1 Bottle 8 \\
\hline 9 & $9(1)$ & 28 & 10 & $\begin{array}{llll}5 & 6 & 1 & 17\end{array}$ & 73 & Same as \#028 + IL 1 Bottle 9 \\
\hline 009_2 & $9(2)^{1}$ & 29 & 11 & $\begin{array}{llll}19 & 7 & 9(1) & 18\end{array}$ & 74 & Same as \#029+ IL 1 Bottle 10 \\
\hline 10 & 10 & 30 & 12 & $\begin{array}{llll}5 & 6 & 16 & 18\end{array}$ & 75 & Same as \#030 + IL 1 Bottle 11 \\
\hline 11 & 11 & 31 & 13 & $\begin{array}{llll}2 & 5 & 12 & 14\end{array}$ & 76 & Same as \#031 + IL 1 Bottle 12 \\
\hline 12 & 12 & 32 & 14 & $\begin{array}{llll}4 & 7 & 9(1) & 11\end{array}$ & 77 & Same as \#032 + IL 1 Bottle 13 \\
\hline 13 & 13 & 33 & 17 & $\begin{array}{llll}1 & 2 & 13 & 9(1)\end{array}$ & 78 & Same as \#033 + IL 1 Bottle 14 \\
\hline 14 & 14 & 34 & 19 & $\begin{array}{llll}7 & 10 & 13 & 15\end{array}$ & 79 & Same as \#034 + IL 1 Bottle 15 \\
\hline 15 & 15 & 35 & 1 & $\begin{array}{llll}8 & 11 & 12 & 19\end{array}$ & 80 & Same as \#035 + IL 2 Batch 1 \\
\hline 16 & 16 & 36 & 2 & $\begin{array}{llll}16 & 14 & 15 & 11\end{array}$ & 81 & Same as \#036 + IL 2 Batch 2 \\
\hline 17 & 17 & 37 & 3 & $\begin{array}{llll}6 & 7 & 14 & 19\end{array}$ & 82 & Same as \#037 + IL 2 Batch 3 \\
\hline 18 & 18 & 38 & 4 & $\begin{array}{llll}12 & 18 & 14 & 19\end{array}$ & 83 & Same as \#038 + IL 2 Batch 4 \\
\hline \multirow[t]{6}{*}{19} & 19 & 39 & 5 & $2 \quad 3 \quad 6 \quad 16$ & 84 & Same as \#039+ IL 2 Batch 5 \\
\hline & & 40 & 7 & $\begin{array}{llll}3 & 12 & 17 & 18\end{array}$ & 85 & Same as \#040+IL 2 Batch 6 \\
\hline & & 41 & 8 & $\begin{array}{llll}5 & 15 & 14 & 17\end{array}$ & 86 & Same as \#041 + IL 2 Batch 7 \\
\hline & & 42 & $9(1)$ & $\begin{array}{llll}4 & 9(1) & 11 & 15\end{array}$ & 87 & Same as \#042 + IL 2 Batch 8 \\
\hline & & 43 & 10 & $\begin{array}{llll}1 & 18 & 9(1) & 13\end{array}$ & 88 & Same as \#043+ IL 2 Batch 9 \\
\hline & & 44 & 11 & $\begin{array}{llll}3 & 16 & 10 & 13\end{array}$ & 89 & Same as \#044 + IL 2 Batch 10 \\
\hline
\end{tabular}


Table 2. Cont.

\begin{tabular}{|c|c|c|c|c|c|c|}
\hline \multicolumn{2}{|c|}{$\begin{array}{l}\text { Single Substrate } \\
\text { Material Burns }\end{array}$} & \multicolumn{3}{|c|}{ Substrate Mixture Material Burns } & \multicolumn{2}{|c|}{ Substrate Mixture Material Burns with IL } \\
\hline Exp \# & Substrate & Exp \# & $\begin{array}{l}\text { Primary } \\
\text { Substrate }\end{array}$ & Secondary Substrates & Exp \# & Substrate + IL \\
\hline & & 45 & 12 & $\begin{array}{llll}7 & 11 & 13 & 14\end{array}$ & 90 & Same as \#045 + IL 2 Batch 11 \\
\hline & & 46 & 13 & $\begin{array}{llll}9(1) & 12 & 14 & 19\end{array}$ & 91 & Same as \#046 + IL 2 Batch 12 \\
\hline & & 47 & 14 & $\begin{array}{llll}7 & 3 & 11 & 19\end{array}$ & 92 & Same as \#047 + IL 2 Batch 13 \\
\hline & & 48 & 17 & $\begin{array}{llll}5 & 9(1) & 13 & 18\end{array}$ & 93 & Same as \#048+ IL 2 Batch 14 \\
\hline & & 49 & 19 & $\begin{array}{llll}5 & 8 & 15 & 17\end{array}$ & 94 & Same as \#049+ IL 2 Batch 15 \\
\hline & & 50 & 1 & $\begin{array}{llll}6 & 10 & 14 & 16\end{array}$ & 95 & Same as \#050 + IL 3 Bottle 1 \\
\hline & & 51 & 2 & $\begin{array}{llll}13 & 5 & 18 & 15\end{array}$ & 96 & Same as \#051 + IL 3 Bottle 2 \\
\hline & & 52 & 3 & $\begin{array}{llll}14 & 10 & 15 & 17\end{array}$ & 97 & Same as \#052 + IL 3 Bottle 3 \\
\hline & & 53 & 4 & $\begin{array}{llll}11 & 12 & 13 & 14\end{array}$ & 98 & Same as \#053 + IL 3 Bottle 4 \\
\hline & & 54 & 5 & $\begin{array}{llll}10 & 14 & 16 & 18\end{array}$ & 99 & Same as \#054 + IL 3 Bottle 5 \\
\hline & & 55 & 7 & $\begin{array}{llll}10 & 11 & 16 & 19\end{array}$ & 100 & Same as \#055 + IL 3 Bottle 6 \\
\hline & & 56 & 8 & $\begin{array}{llll}1 & 5 & 13 & 14\end{array}$ & 101 & Same as \#056 + IL 3 Bottle 7 \\
\hline & & 57 & $9(2)$ & $\begin{array}{llll}2 & 19 & 13 & 16\end{array}$ & 102 & Same as \#057 + IL 3 Bottle 8 \\
\hline & & 58 & 10 & $\begin{array}{llll}3 & 5 & 14 & 16\end{array}$ & 103 & Same as \#058 + IL 3 Bottle 9 \\
\hline & & 59 & 11 & $\begin{array}{llll}8 & 12 & 16 & 17\end{array}$ & 104 & Same as \#059 + IL 3 Bottle 10 \\
\hline & & 60 & 12 & $\begin{array}{llll}6 & 14 & 15 & 5\end{array}$ & 105 & Same as \#060 + IL 3 Bottle 11 \\
\hline & & 61 & 13 & $\begin{array}{llll}2 & 14 & 15 & 16\end{array}$ & 106 & Same as \#061 + IL 3 Bottle 12 \\
\hline & & 62 & 14 & $\begin{array}{llll}1 & 3 & 19 & 16\end{array}$ & 107 & Same as \#062 + IL 3 Bottle 13 \\
\hline & & 63 & 17 & $\begin{array}{llll}5 & 9(1) & 10 & 6\end{array}$ & 108 & Same as \#063 + IL 3 Bottle 14 \\
\hline & & 64 & 19 & $\begin{array}{llll}17 & 3 & 12 & 16\end{array}$ & 109 & Same as \#064 + IL 3 Bottle 15 \\
\hline
\end{tabular}

${ }^{1}$ Two batches of curtain were used in this study due to a shortage of material to perform one set of experiments (57 and 102). The same batch was not available, since most of the materials were obtained second hand.

\subsection{Protocol for Burn Experiments}

All burn experiments were performed in a fire- and explosion-proof "bunker", of the Netherlands Forensic Institute. Appropriate safety measures in line with the institute guidelines were taken throughout the study to prevent personal injuries and fire related damage to the infrastructure.

A total amount of $300 \mathrm{~g}$ of substrate was placed on an uncoated stainless-steel grill plate (Barbecook Grillpan-RVS) $(345 \mathrm{~mm} \times 240 \mathrm{~mm})$. The stainless-steel grill plate contained small holes that limited the heating of the grill-plate and promoted the oxygen supply during the fire. For each experiment a new grill plate was used (single use) to prevent cross contamination. Various amounts of substrates and ignitable liquids, different absorption times, ignitable liquid application methods, ignition methods, and burn times were tested. This led to an approach with several fixed parameters to control the fire experiments and create comparable conditions as much as possible. A typical experiment involved one primary and four secondary substrates (see Table 2), configured as illustrated in Figure 1. The primary substrate always represented $60 \%$ of the total amount of material (180 out of $300 \mathrm{~g}$ ). To this a volume of $15 \mathrm{~mL}$ of IL was applied, evenly divided over three separate parallel lines using a glass Pasteur pipette (indicated by the dotted arrows in Figure 1). The IL was applied from right to left following the numbered arrows in Figure 1A,B. After allowing the IL to be absorbed for five minutes the samples were ignited using a gas torch. The point of ignition is indicated with a star in Figure 1. The fires were left to burn freely for eight minutes and extinguished with water (approximately 20 to $30 \mathrm{~mL}$ ) using a common hand pressure spray bottle. The eight minute burn time was chosen based on the average fire department response time in the Netherlands in 2015 [29], and was therefore considered to be realistic. From the test experiments and screening with GC-flame-ionization detector (FID) it was observed that with a burn time of eight minutes, reducing the amount of material $(<300 \mathrm{~g})$, and ignitable liquid $(<15 \mathrm{~mL})$ lead to complete consumption of the substrate. According to Stauffer et al. [1], it is recommended to have at least one-third of the substrate material partially burnt/intact in fire experiments, the parameters were chosen as indicated above.

After allowing the debris to cool (approximately $30 \mathrm{~min}$ ), the entire sample was manually transferred to glass jars (VTS-Politie, The Netherlands) using a stainless-steel spatula. The glass jars were weighed before and after collecting the fire debris to estimate how much material (debris 
plus residual water) was recovered after a burn. Depending on the extent of the fire, recoveries were in the range of $30-108 \%$ with an average value of $78 \%$.

The grill plates were positioned on a purpose-built steel table (ca. $2 \mathrm{~m} \times 0.8 \mathrm{~m}$ ). Three ordinary construction bricks (ca. $250 \mathrm{~mm} \times 100 \mathrm{~mm} \times 50 \mathrm{~mm}$ ) were positioned underneath each grill plate. A maximum of four fire experiments were conducted simultaneously. In order to prevent contamination between different fires glass wool plates were placed as a barrier between the blanks and IL burns as is illustrated in Figure 2.
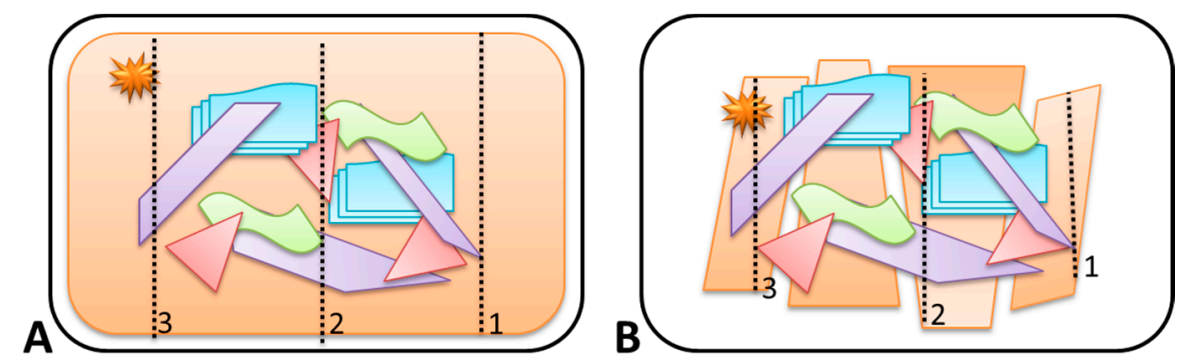

Figure 1. Schematic representation of the general lay-out of the burn experiments. IL was applied along three parallel traces, from right to left as indicated by the numbering. In the schematic drawing, the primary substrate is a carpet (A) or wood flooring of laminate (B). Secondary substrates are indicated in purple (wood), green (textile), blue (paper), and plastic (red).

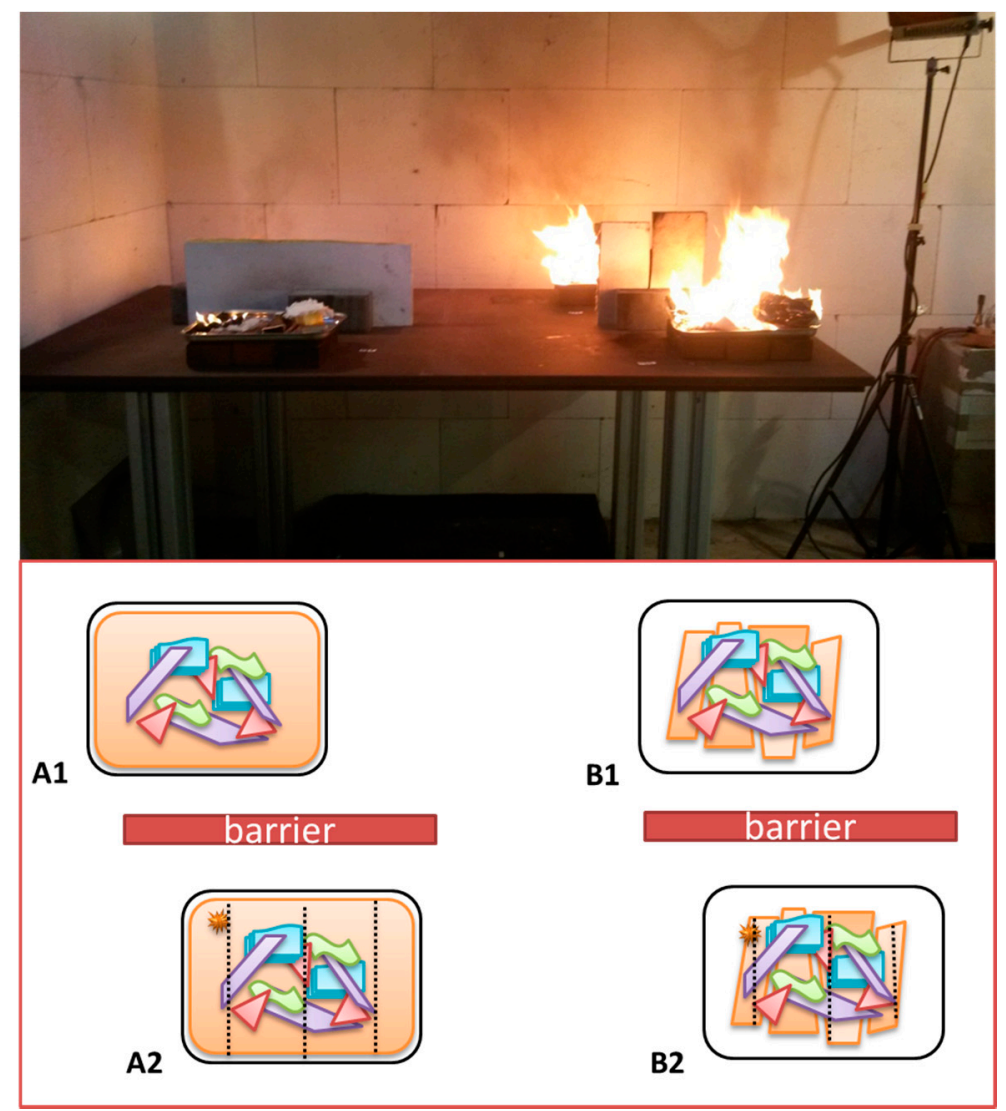

Figure 2. Schematic representation of the positioning of the different grill plates on the steel table and a photograph of a typical fire experiment. On the left two plates of substrate combination (A), (A1) is the blank and (A2) has IL added. On the right two plates of substrate combination (B), (B1) is blank and (B2) with IL added. 
In Figure 3 some real examples are given of the experimental setup for the burn experiments.

All photographs regarding the experimental setup and burns can be found in Photographs S1 of the Supplementary Information. In Video S1 of the Supplementary Information a two-minute video can be seen of a typical fire experiment as performed in this study.

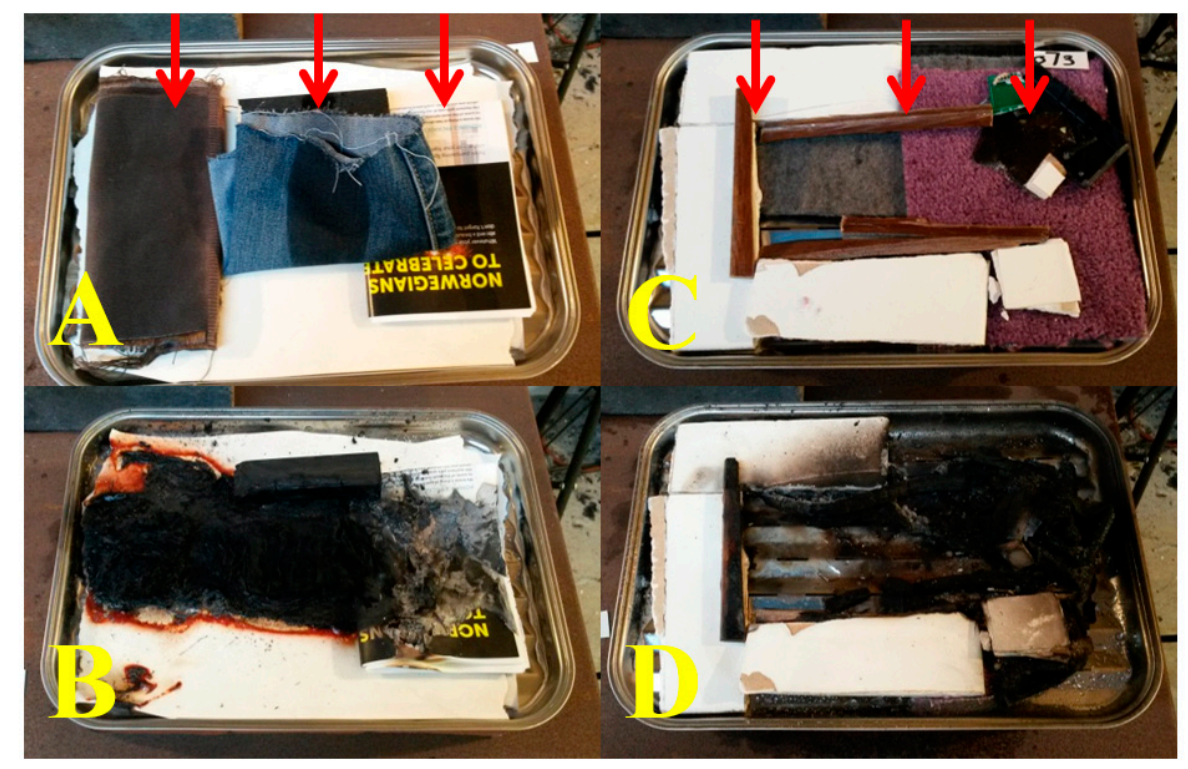

Figure 3. Experimental setup of small scale fires. (A,C) show intact substrates to which $15 \mathrm{~mL}$ of white spirit has been applied in three vertical lines (indicated with red arrows) and (B,D) are the corresponding fire debris samples. Substrates for (A,B): vinyl flooring (primary substrate, $60 \mathrm{wt} \%$ ), plus curtain, wooden chair, magazine, and clothing (secondary substrates, $10 \mathrm{wt} \%$ each); substrates for (C,D): plasterboard (60 wt \%), carpet material, carpet underlay, floor skirting, and computer fragments (monitor, print boards, and cables) (10 wt \% each).

\subsection{Preparation of Headspace Extracts}

All fire debris samples were analyzed according to an adapted version of the standard protocol used at the Netherlands Forensic Institute for casework. For headspace analysis the lid of the jar was punctured with a thumbtack and sealed with a piece of aluminium tape. The jars were then placed in an oven at $70{ }^{\circ} \mathrm{C}$ for at least $4 \mathrm{~h}$. Subsequently, a screening analysis was performed. The main purpose of the screening is to determine the appropriate sampling volume for the extraction. The appropriate headspace volume is determined from the maximum intensity observed in the GC-FID run. During the screening, the jars were resealed with fresh aluminium tape and re-inserted in the oven at $70{ }^{\circ} \mathrm{C}$ until the headspace volume needed for GC $\times$ GC analysis was known.

Extracts for GC $\times \mathrm{GC}$ analysis were prepared by aspiring a suitable headspace volume through a glass cartridges ( $6 \mathrm{~mm}$ O.D. $\times 70 \mathrm{~mm}$ ) containing $100 / 50 \mathrm{mg}$ of sorbent (Anasorb CSC Coconut Shell Charcoal tubes, SKC Inc., Eighty Four, PA, USA) using a 100-mL gas-tight syringe. Depending on the maximum signal intensity, different volumes were aspired. For a maximum signal intensity (highest peak) below $80 \mathrm{pA}$ a volume of $300 \mathrm{~mL}$ of headspace was sampled (3 syringe volumes). For signals between 80 and $300 \mathrm{pA}$ this volume was $100 \mathrm{~mL}$ (1 syringe volume), and for signals exceeding $300 \mathrm{pA}$ this volume was $50 \mathrm{~mL}$ (half a syringe volume). The charcoal cartridge was connected to the syringe by removing both ends using a glass cutter and connecting a needle on one end and the syringe on the other, using two pieces of silicon tubing. After the headspace sampling the glass tube was cut and the charcoal contents were collected in plastic microcentrifuge vials (Safe-lock tubes, $2.0 \mathrm{~mL}$, Eppendorf AG, Hamburg, Germany). To each vial $1 \mathrm{~mL}$ of DCM containing $0.01 \mathrm{mg} / \mathrm{mL}$ chlorobenzene IS was added. After centrifuging for $15 \mathrm{~min}$ at $(13,000 \mathrm{rpm})$ the supernatant was transferred using a glass 
Pasteur pipette to a standard clear glass 1.5-mL GC vial and capped for analysis. Prior to analysis the extracts were stored in a refrigerator at $4{ }^{\circ} \mathrm{C}$.

\subsection{Instrumental Analysis}

\subsubsection{GC-FID}

Screening analyses were performed on an Agilent Technologies 6890A Network GC System equipped with an Agilent Technologies 7683B Series Injector and an Agilent Technologies 7683B Series Autosampler (all from Agilent, Santa Clara, CA, USA). For the chromatographic separation an Agilent medium-polarity DB-624 (6\% cyanopropyl-phenyl, 94\% dimethyl polysiloxane) column (30 $\mathrm{m} \times 320 \mu \mathrm{m}$ i.d.; $1.8 \mu \mathrm{m}$ film thickness) was used. Helium was used as the carrier gas at a constant flow of $2 \mathrm{~mL} / \mathrm{min}$. A headspace volume of $0.5 \mathrm{~mL}$ was injected with a split ratio of 20:1 and for analysis the following oven temperature program was applied: $80^{\circ} \mathrm{C}$ with $2 \mathrm{~min}$ hold, followed by a linear ramp of $40^{\circ} \mathrm{C} / \mathrm{min}$ to $255^{\circ} \mathrm{C}$ with a $5 \mathrm{~min}$ hold. Both the injector temperature and the detector temperature were set to $250{ }^{\circ} \mathrm{C}$. Data were collected at a rate of $200 \mathrm{~Hz}$.

\subsubsection{GC $\times$ GC-FID}

GC $\times$ GC-FID experiments were performed on an Agilent Technologies 6890N Network GC System with a LECO (Da Vinci, Rotterdam, The Netherlands) dual-stage, quad-jet thermal modulator and a FID (Agilent). For all injections a CTC Analytics GC Pal Autosampler (GLSciences, Veldhoven, The Netherlands) was used. An Agilent DB-1 (100\% dimethylpolysiloxane) first-dimension column $(30 \mathrm{~m} \times 250 \mu \mathrm{m}$ i.d. $\times 0.5 \mu \mathrm{m}$ film thickness) was used in combination with an Agilent DB-17 ((50\%-Phenyl)-methylpolysiloxane) second-dimension column $(1 \mathrm{~m} \times 100 \mu \mathrm{m}$ i.d. $\times 0.2 \mu \mathrm{m}$ film thickness). The columns were connected via a blue-tube Meltfit (NLISIS, Veldhoven, The Netherlands). Samples were measured in a randomized order across a time span of four weeks. The dataset included a repeat of the performance test solution after every 15 injections. Blank injections were also performed regularly to exclude possible carry-over effects of high concentration fire debris samples. A volume of $1 \mu \mathrm{L}$ of the extracts was injected in splitless mode. Helium was used as a carrier gas at a constant pressure of $110 \mathrm{kPa}$. The purge time was set at $90 \mathrm{~s}$. The temperature program for the first-dimension separation was $45^{\circ} \mathrm{C}$ initial with $0.5 \mathrm{~min}$ hold, followed by a linear ramp of $1{ }^{\circ} \mathrm{C} / \mathrm{min}$ to a temperature of $80^{\circ} \mathrm{C}$, a linear ramp of $3{ }^{\circ} \mathrm{C} / \mathrm{min}$ to a temperature of $130^{\circ} \mathrm{C}$ and finally a linear ramp of $5.5^{\circ} \mathrm{C} / \mathrm{min}$ to a final temperature of $255^{\circ} \mathrm{C}$ with a $10 \mathrm{~min}$ hold time. An offset of $+5{ }^{\circ} \mathrm{C}$ above the primary oven was used for the second-dimension oven in the system with a parallel temperature program. The modulator temperature offset was $+10^{\circ} \mathrm{C}$. The injector temperature was set at $250{ }^{\circ} \mathrm{C}$ and the FID detector temperature was $280^{\circ} \mathrm{C}$. A modulation time of $4 \mathrm{~s}$ was applied during the entire run, with a hot-pulse time of $400 \mathrm{~ms}$. Data were collected at a rate of $200 \mathrm{~Hz}$.

\subsubsection{GC $\times$ GC-TOFMS}

GC $\times$ GC-TOFMS experiments for identification were carried out on an Agilent Technologies 6890N GC System with a LECO dual-stage, quad-jet thermal modulator coupled to a Pegasus III time-of-flight (TOF) MS (LECO). Samples were injected using an autosampler of Gerstel (Mülheim an der Ruhr, Germany). An identical column set was used as for the GC $\times$ GC-FID system. The columns were connected via an universal presstight connector (Siltek, Restek, Bellefonte, PA, USA). Fire debris extracts were injected as such. Both extracts and the performance test mixture were injected in splitless mode with an injection volume of $1 \mu \mathrm{L}$. Diluted neat ignitable liquids were analyzed in split mode at a split ratio of 30:1 and an injection volume of $1 \mu \mathrm{L}$. Analysis were carried out at a constant pressure of $110 \mathrm{kPa}$ with helium as carrier gas. The following temperature program for the programmed temperature vaporizer (PTV) injector (Gerstel Cooled Injection System (CIS) 4) was applied: initial temperature of $40^{\circ} \mathrm{C}$ with a hold time of $0.1 \mathrm{~min}$, followed by a linear ramp of $12{ }^{\circ} \mathrm{C} / \mathrm{s}$ to a final temperature of $250^{\circ} \mathrm{C}$ until the end of the run. For the first-dimension separation the oven temperature 
program was set as follows: initial temperature of $45^{\circ} \mathrm{C}$ with a hold time of $0.5 \mathrm{~min}$, followed by a linear ramp of $1^{\circ} \mathrm{C} / \mathrm{min}$ to a temperature of $80^{\circ} \mathrm{C}$, followed by a second linear ramp of $3^{\circ} \mathrm{C} / \mathrm{min}$ to a temperature of $130{ }^{\circ} \mathrm{C}$, and finally a linear ramp of $5.5^{\circ} \mathrm{C} / \mathrm{min}$ to a final temperature of $255^{\circ} \mathrm{C}$ with a hold time of $10 \mathrm{~min}$. A parallel temperature program was used in the second oven with an offset of $+5{ }^{\circ} \mathrm{C}$ above the primary oven. The modulator temperature offset was $+10^{\circ} \mathrm{C}$. The modulation time was $4 \mathrm{~s}$ with a hot-pulse duration of $400 \mathrm{~ms}$. The inlet temperature was held at $250{ }^{\circ} \mathrm{C}$. The MS transfer-line temperature was maintained at $225^{\circ} \mathrm{C}$. The ion-source temperature was $250{ }^{\circ} \mathrm{C}$ with an electron impact (EI) energy of $70 \mathrm{eV}$. Due to the large solvent peak a solvent delay of $350 \mathrm{~s}$ was applied. Data were acquired using an acquisition rate of $200 \mathrm{~Hz}$, covering a 35-500 amu mass range.

\section{Results and Discussion}

\subsection{GC $\times$ GC-FID Method Development}

Because of the great variety in substrate materials, the different types of ignitable liquids used for this study and the inherent chemical complexity of the fire debris matrix, an optimized comprehensive separation method is required to effectively analyze all compounds of interest. Different columns, varying in internal diameter and film thickness were tested at different $\mathrm{GC} \times \mathrm{GC}$ conditions to determine the optimal settings with respect to carrier-gas pressure, initial temperature, temperature program, modulation time, hot-pulse time, and purge time. Based on initial experiments involving gasoline, which is the most volatile IL compared to white spirit and lamp oil, a nonpolar DB-1 column with a reasonably thick film $(30 \mathrm{~m} \times 250 \mu \mathrm{m}$ i.d. $\times 0.5 \mu \mathrm{m})$ was selected for the first dimension. A DB-17 $(1 \mathrm{~m} \times 100 \mu \mathrm{m}$ i.d. $\times 0.2 \mu \mathrm{m}$ film thickness $)$ medium-polar column with an equal phase ratio ( $\beta$, the ratio of the mobile-phase volume to the stationary-phase volume) of 125 was chosen for the second dimension. It was important to determine the optimal purge time for splitless injection that allowed maximum vaporization of the sample, while providing good precision (low relative standard deviation, RSD). For this purpose a performance test mixture was subjected to variable purge time. Based on these data a purge time of $90 \mathrm{~s}$ was selected. For further optimization an IL mixture was used, consisting of equal amounts of white spirit (IL1, bottle 1), gasoline (IL2, batch 8), and lamp oil (IL3, bottle 2). Figure 4 shows an example of the GC $\times$ GC analysis of the IL mixture under optimized conditions.

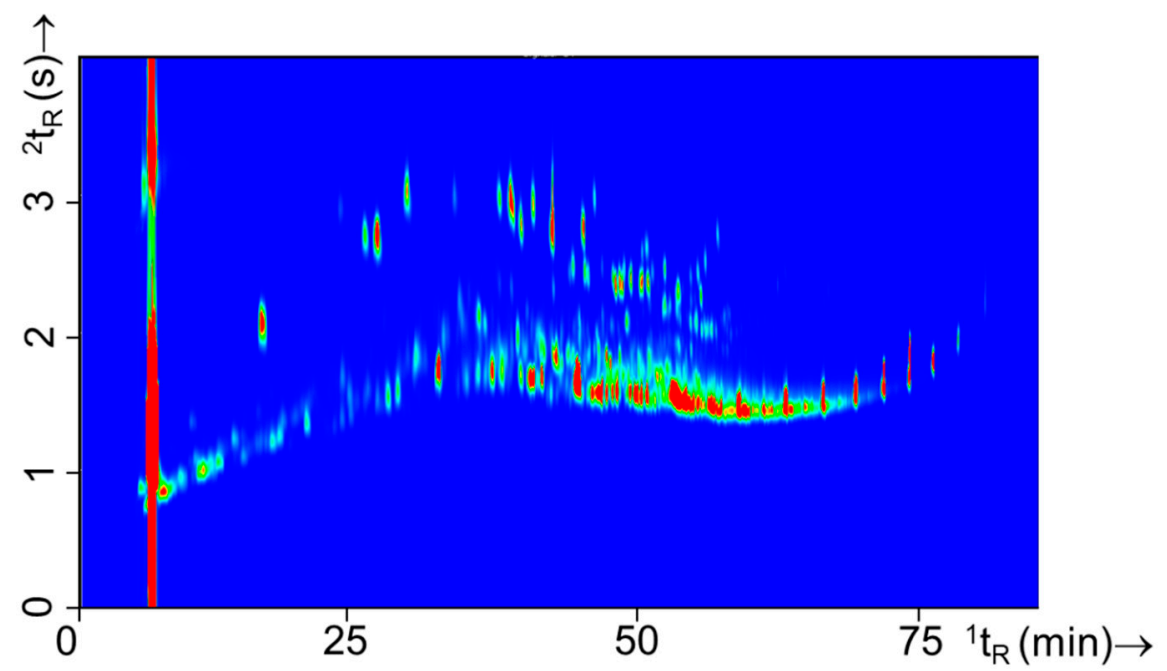

Figure 4. GC $\times$ GC-FID contour plot of IL mixture under optimized separation method.

RSD values of the internal standard chlorobenzene for the ${ }^{1} \mathrm{D}$ and the ${ }^{2} \mathrm{D}$ retention times and the summed peak area are shown in Table 3. For all samples IS spiked DCM was used as the solvent. It has a boiling point of $40^{\circ} \mathrm{C}$, close to that of the most volatile compounds in gasoline. Therefore, it was 
difficult to effectively trap early eluting components in the modulator and some "wrap-around" [30] was observed during approximately the first ten minutes in the $\mathrm{GC} \times \mathrm{GC}$ chromatogram. To minimize wrap-around a modulation time of $4 \mathrm{~s}$ was used, with a hot-pulse time of $400 \mathrm{~ms}$.

The data shown in Table 3 illustrate the observed variation for a given setup over a period of two weeks. During the entire measurement campaign the column system had to be reinstalled once due to use of the system for another experiment. This had no effect on peak areas but resulted in slight retention time shifts. Combining all data for the standards results in an RSD of $1-2 \%$ and $2-4 \%$ in the retention time in the first and second dimension, respectively. Overall the optimized methods, as described in Section 2, yielded satisfactory separation performance and repeatability.

Table 3. RSD values calculated for the internal standard for fire debris samples and intact ILs.

\begin{tabular}{ccccccccc}
\hline & \multicolumn{4}{c}{ Fire Debris } & \multicolumn{3}{c}{ ILs } \\
\hline Compounds & $n^{\mathbf{1}}$ & ${ }^{1} \mathbf{D}_{\operatorname{tr}}(\mathbf{s})$ & ${ }^{2} \mathbf{D}_{\operatorname{tr}}(\mathbf{s})$ & Area & $n$ & ${ }^{\mathbf{1}} \mathbf{D}_{\operatorname{tr}}(\mathbf{s})$ & ${ }^{\mathbf{2}} \mathbf{D}_{\operatorname{tr}}(\mathbf{s})$ & Area \\
\hline Chlorobenzene & 43 & $0.09 \%$ & $1.74 \%$ & $23.14 \%$ & 37 & $0.08 \%$ & $0.14 \%$ & $16.42 \%$ \\
\hline \multicolumn{4}{c}{ Number of experiments on which these numbers are based. }
\end{tabular}

\subsection{Characterization of ILs}

Three types of ILs were used in this study, i.e., white spirit, gasoline, and lamp oil. These ILs are frequently encountered in arson investigations in the Netherlands. Of each class 15 batches/bottles were purchased at various locations (see for full details Table S1). Figure 5 shows a typical GC $\times$ GC-TOFMS total ion current (TIC) profile of neat white spirit, gasoline, and lamp oil, respectively. The comprehensive chromatographic profiles of these intact ILs are distinctively different, and hence it is straight forward to establish the type of IL analyzed. Such a classification of intact IL is also easily obtained from GC-MS data and does not necessarily require a comprehensive separation. However, the GC $\times$ GC contour plots clearly reveal much more information on the chemical composition thus facilitating the IL recognition.

For each IL class, typical compounds were identified by searching the MS spectra against the NIST/EPA/NIH Mass Spectral Database (NIST11). Compounds were assigned on the basis of peak purity, the MS match score, as reported by the MS database, and personal assessment and interpretation of the spectra. In Table S2 compounds are listed that were identified according to these guidelines. This table is not exhaustive with respect to IL composition but rather gives an overview of compounds that typically are found for a given class of IL. It should be noted that chemical identification was not confirmed on the basis of retention time comparison against standards and hence the compound assignment is still tentative. Figure collections S1, S2, and S3 of the Supplemental Information includes all chromatograms for white spirit, gasoline, and lamp oil, respectively. Recently, the Sigman team reported a very extensive overview of compounds found in ILs and burned substrates in the Ignitable Liquids Reference Collection (ILRC) and Substrate databases [31]. Our findings were compared against the table this group presented in Appendix E of their article. In this table identified compounds are listed according to the ASTM E 1618-14 classification scheme of ILs [2]. According to this framework the ILs in this study belong to the class gasoline (gasoline), medium petroleum distillates (white spirit), and other-miscellaneous (lamp oil [13]). In Table S2 compounds that were found in both studies were highlighted green. However, not all compounds listed in Appendix E of [31] were encountered in this work, but when only considering frequently occurring components (frequency of occurrence in the ILRC database exceeding 0.25) all listed compounds for all three class of ILs were identified.

From a forensic point of view, it is also interesting to evaluate the possibility for within-class differentiation of ignitable liquids as this could lead to a higher evidential value for a "matching" chemical profile. In a previous study [6], within-class differences were thoroughly discussed for white spirits. From the findings of this study it became clear that for this specific crude-oil derivative differences were mainly observed over time, which is related to the manufacturing, distribution, 
and the broad specification of this product. In this study within-class differences were observed for all three IL types but differences were most pronounced for gasoline. Various approaches to distinguish gasoline samples are described in literature, such as (i) substituted naphthalenes [7,32]; (ii) alkylate compounds [9]; and (iii) octane rating [33]. Figure 6 shows an example of two different gasoline batches and the variation observed.
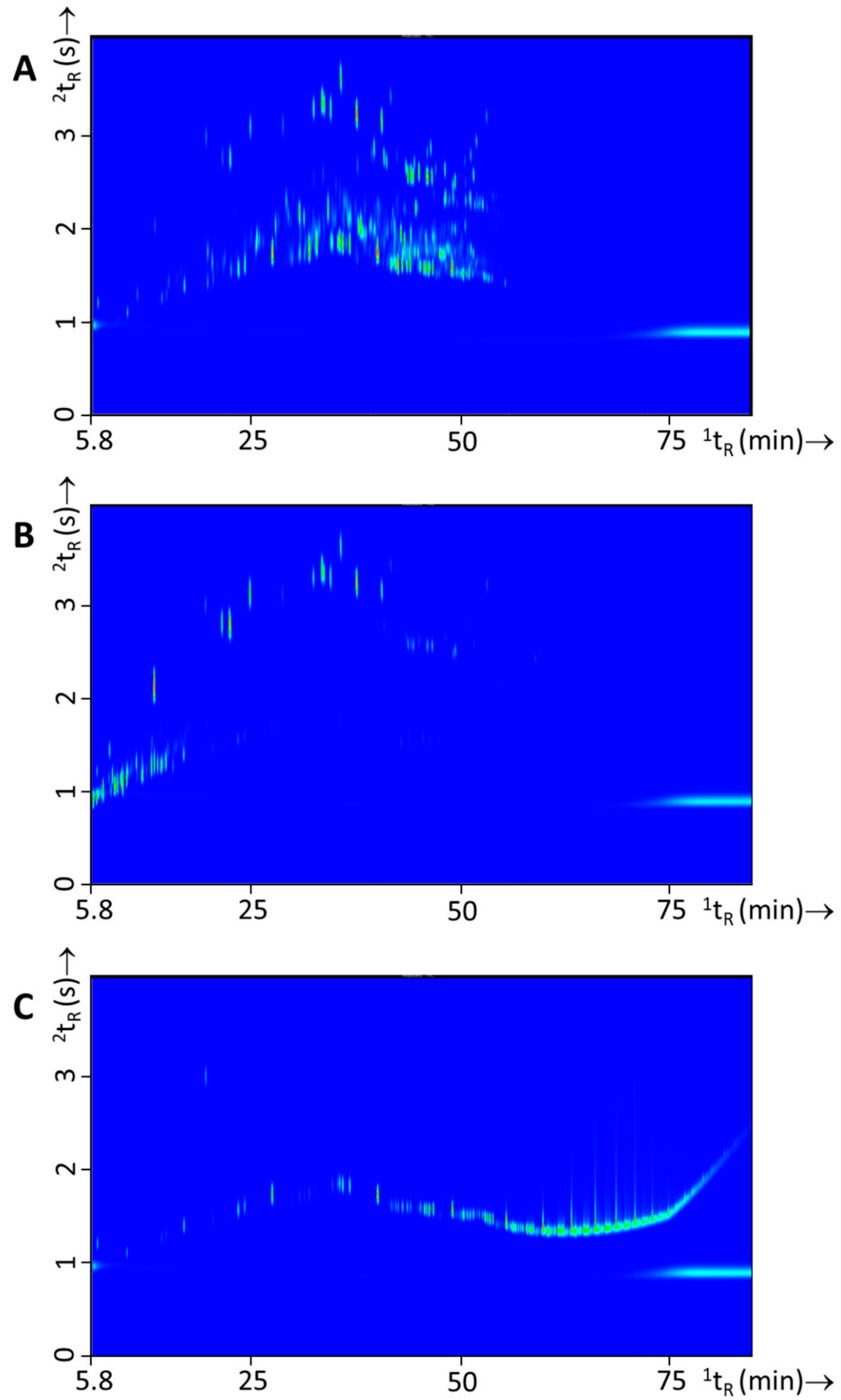

Figure 5. Typical GC $\times$ GC-TOFMS TIC contour plots of each of the three classes IL used in this study, i.e., (A) white spirit (experiment 110), (B) gasoline (experiment 139), and (C) lamp oil (experiment 151). 


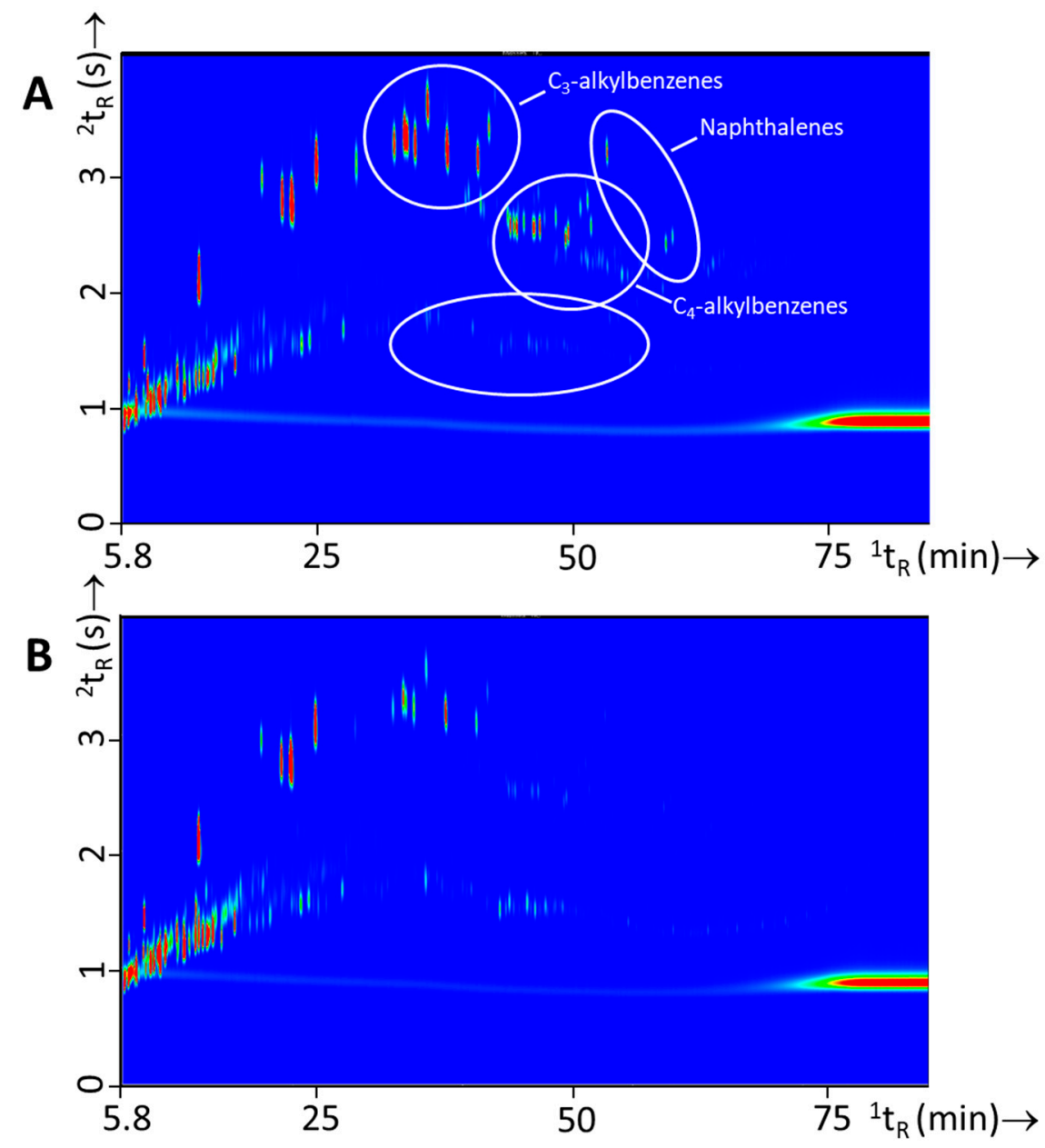

Figure 6. GC $\times$ GC-TOFMS TIC contour plots of two different batches of gasoline with (A) experiment 127 (Shell) and (B) experiment 129 (BP). Differences in the samples are highlighted with white circles.

Differences in this particular example was caused by the presence of the naphthalenes in Figure $6 \mathrm{~A}$, the different ratios of $\mathrm{C}_{3^{-}}$and $\mathrm{C}_{4}$-alkylbenzenes and the alkane profiles. In a study of Sandercock et al. [7,32] on the chemical profiling of unevaporated and evaporated gasoline samples it was shown that substituted naphthalenes are distinctive markers to differentiate gasoline samples. In this study we have investigated whether such differences are substantial enough and whether comprehensive gas chromatographic analysis is powerful enough to determine which gasoline was used on the basis of fire debris residue analysis (see Section 3.4).

\subsection{Fire Experiments without IL: Headspace and Pyrolysis Compounds from Single Substrates and} Substrate Mixtures

Nineteen different substrates were used throughout this study. The experimental design (Table 2) consisted of separate burns of single substrates and combinations of these substrate mixtures. Substrate mixtures were included as real fires typically include a wide variety of materials. A total of 45 combinations were created that were set on fire with and without IL. Prior to analyzing the substrate mixtures with IL, the single substrates and substrate mixtures burns without IL were studied to gain insight in the chemical headspace composition resulting from the substrates. Figure 7 shows and example of a typical substrate mixture (experiment 24) consisting of carpet material as primary substrate and oak floor strips, carpet underlay, computer fragments, and electronics as secondary 
substrates. All other GC $\times$ GC-TOFMS contour plots of the single substrates and substrate mixtures can be found in Figures S4 and S5, respectively.

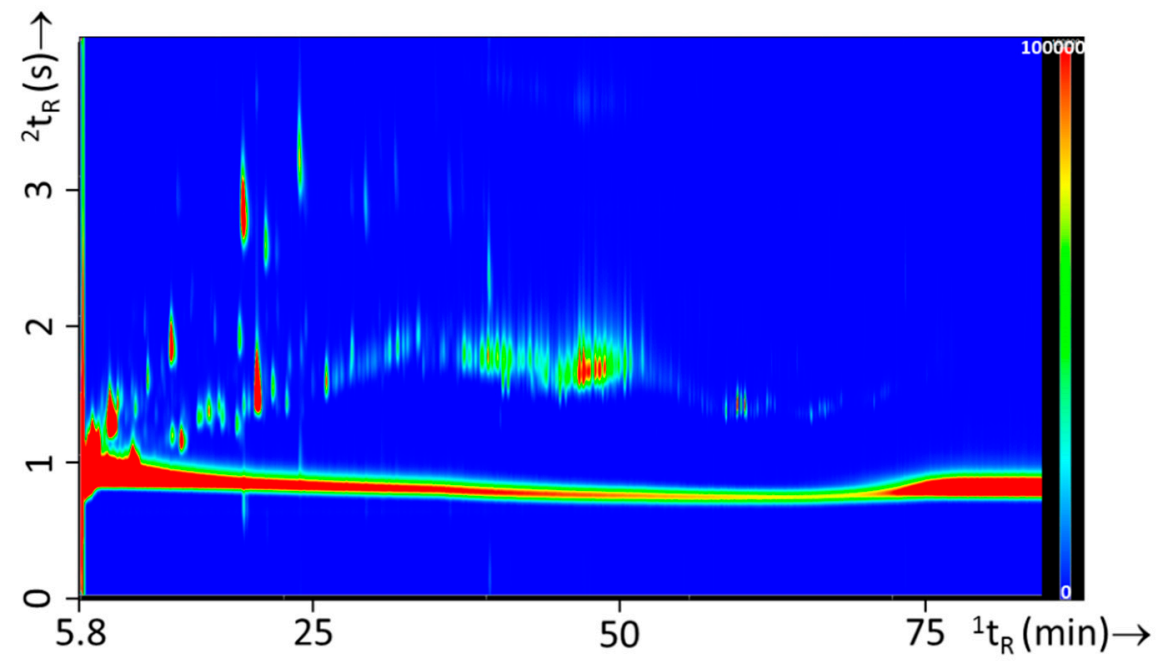

Figure 7. GC $\times$ GC-TOFMS TIC contour plot of a substrate mixture (experiment 24 ) containing carpet as the primary substrate and oak floor strips, carpet underlay, computer fragments, and electronic parts as secondary substrates.

In Table S3 of the Supplementary Information a list of identified substrate compounds can be found. These compounds are either emitted from the substrate due do the high temperature or are formed during the burning of the substrate. It should be noted that this list is not exhaustive, not all compounds could be identified (due to incomplete separation, low matching scores, or low headspace concentration). Nonetheless, the table provides an overview of typical compounds present in the headspace after burning of a particular substrate. The chemical composition of the substrate mixtures fires were compared to those of the individual substrates to investigate whether the combined burning of various materials could lead to new compounds being formed and released in the headspace. After careful examination of the GC $\times$ GC-TOFMS data no additional compounds were found in the headspace of substrate mixture burn residues.

From Table S3, compounds were selected and listed in Table 4 that were identified only in the substrate fire experiments and not in the intact ILs. This table also includes a comparison to the list of the Sigman group as presented in Appendix D of their article [31]. In this appendix 47 major compounds were listed that were identified in burned substrates only and not in ILs as major compounds. From Appendix D only seven compounds were found in the burned substrates in the current work and the frequency of occurrences were also noted for these seven. Although at first sight the results in both studies do not seem highly comparable, several factors can explain these differences. The low frequency of occurrence ( 0.38 or less), as reported by Akmeemana et al. [31], indicate that a wide range of headspace compounds can be encountered. Additionally, high volatility, incomplete separation, low MS database matching scores, or low headspace concentration might have limited the identification in the current work. Finally, it should also be noted that Appendix D lists compounds identified in 106 burned substrates, which covers a much larger range of materials than used in our study.

Some of the compounds identified in the headspace of the burnt substrates are also present in the ILs. For a correct forensic interpretation of fire debris analysis results it is very important to be aware of such ambiguous origins, and therefore these compounds are reported separately in Table 5. 
Table 4. Compounds identified from substrate fire experiments and not found in the intact ILs with the corresponding frequency of occurrences from Appendix D of the Sigman group [31].

\begin{tabular}{|c|c|c|}
\hline Compound & Substrates & $\begin{array}{l}\text { Frequency of } \\
\text { Occurrences [31] }\end{array}$ \\
\hline methyl methacrylate & Mattress, computer fragments, electronics & - \\
\hline pentanal & $\begin{array}{l}\text { Floor skirting, pine floor strips, laminate flooring, living-room rug, } \\
\text { plasterboard, particle board, wooden chair, newspaper }\end{array}$ & - \\
\hline 1,4-dioxine & Vinyl flooring & - \\
\hline methyl isobutyl ketone & $\begin{array}{l}\text { Floor skirting, pine floor strips, oak floor strips, laminate Flooring, } \\
\text { carpet material, carpet underlay, living-room rug, Particle board, } \\
\text { sofa, wooden chair, mattress, magazines, Newspaper, clothing }\end{array}$ & - \\
\hline butyl ester acetic ester & Floor skirting, carpet underlay, sofa, wooden chair & - \\
\hline cyclopentanone & Carpet underlay, plasterboard, magazines, newspaper, Electronics & $9 \times 10^{-3}$ \\
\hline $2 n$-butylcrolein & Laminate flooring, particle board & - \\
\hline styrene & $\begin{array}{l}\text { Laminate flooring, carpet material, living-room rug, vinyl flooring, } \\
\text { curtains, plasterboard, sofa, mattress, magazines, newspaper, } \\
\text { computer fragments, clothing, electronics }\end{array}$ & $2.4 \times 10^{-1}$ \\
\hline 4-methyl-2-heptanone & Carpet material, carpet underlay, living-room rug & - \\
\hline 4,6-dimethyl-2-heptanone & Carpet underlay & - \\
\hline n-butyl methacrylate & Electronics & - \\
\hline a-methylstyrene & Computer fragments, electronics & $2 \times 10^{-2}$ \\
\hline 2-ethyl-1-hexanol & Electronics & $5 \times 10^{-2}$ \\
\hline butylbenzene & Electronics & - \\
\hline a-pinene & $\begin{array}{l}\text { Floor skirting, pine floor strips, laminate flooring, plasterboard, } \\
\text { particle board, sofa }\end{array}$ & - \\
\hline camphene & Floor skirting, pine floor strips, particle board & - \\
\hline b-pinene & Pine floor strips, particle boards & - \\
\hline 2-pentylfuran & Pine floor strips, plasterboard, sofa, magazines, newspaper & $4 \times 10^{-2}$ \\
\hline nonanal & $\begin{array}{c}\text { Curtains(2), plasterboard, sofa, magazines, newspaper, } \\
\text { Clothing, electronics }\end{array}$ & $9 \times 10^{-3}$ \\
\hline decanal & Plasterboard, sofa, mattress, clothing & - \\
\hline undecanal & Plasterboard & - \\
\hline dodecanal & Plasterboard & - \\
\hline tridecanal & Plasterboard & - \\
\hline nonanoic acid & Mattress, clothing, electronics & - \\
\hline dibutyl phthalate & Mattress, clothing, electronics & $9 \times 10^{-3}$ \\
\hline 1-chloro-decane & Plasterboard & - \\
\hline 1-chloro-undacane & Plasterboard & - \\
\hline butyl acrylate & Carpet underlay & - \\
\hline 2-hexanone & Floor skirting & - \\
\hline pentanitrile & Floor skirting & - \\
\hline 2-propylfuran & Floor skirting & - \\
\hline benzaldehyde & Particle board & $2.3 \times 10^{-1}$ \\
\hline camphor & Particle board & - \\
\hline fenchone & Particle board & - \\
\hline a-terpineol & Particle board & - \\
\hline
\end{tabular}


Table 5. Compounds identified in both burned substrates and intact ILs with their corresponding frequency of occurrences from Table 2 of the Sigman group article.

The ' $x$ ' refers to compounds visibly present in the IL; the ' $t$ ' indicates compounds that are present on trace level.

\begin{tabular}{|c|c|c|c|c|c|c|}
\hline \multirow[t]{2}{*}{ Compound } & \multirow[t]{2}{*}{ Substrates } & \multirow[t]{2}{*}{ White Spirit } & \multirow[t]{2}{*}{ Gasoline } & \multirow[t]{2}{*}{ Lamp Oil } & \multicolumn{2}{|c|}{$\begin{array}{l}\text { Frequency of Occurrences } \\
\qquad[31]\end{array}$} \\
\hline & & & & & IL & Substrate \\
\hline tetrahydrofuran & Curtains (1) & $\mathrm{t}$ & $\mathrm{t}$ & - & - & - \\
\hline benzene & $\begin{array}{l}\text { Floor skirting, carpet material, carpet underlay, living-room rug, vinyl flooring, } \\
\text { curtains, plasterboard, computer fragments, clothing, electronics }\end{array}$ & $\mathrm{t}$ & $\mathrm{x}$ & - & - & - \\
\hline 2-pentanone & $\begin{array}{c}\text { Floor skirting, pine floor strips, carpet material, carpet underlay, living-room rug, } \\
\text { plaster board, magazines, newspaper }\end{array}$ & $\mathrm{t}$ & $\mathrm{x}$ & - & - & - \\
\hline heptane & $\begin{array}{l}\text { Floor skirting, oak floor strips, carpet material, curtains (1), particle board, sofa, } \\
\text { wooden chair, mattress, magazines }\end{array}$ & $\mathrm{x}$ & $\mathrm{x}$ & $\mathrm{x}$ & - & - \\
\hline 2,4-dimethylfuran & Carpet underlay & $\mathrm{x}$ & - & - & - & - \\
\hline toluene & $\begin{array}{l}\text { Floor skirting, pine floor strips, laminate flooring, carpet material, carpet underlay, } \\
\text { living-room rug, vinyl flooring, curtains (2), plaster board, particle board, sofa, wooden } \\
\text { chair, mattress, magazines, newspaper, computer fragments, clothing, electronics }\end{array}$ & $\mathrm{x}$ & $\mathrm{x}$ & - & $1.81 \times 10^{-1}$ & $2.3 \times 10^{-1}$ \\
\hline isobutyl acetate & Floor skirting, oak floor strips & $\mathrm{x}$ & - & - & - & - \\
\hline 4-ethenyl cyclohexane & Carpet material, living-room rug, magazines, computer fragments, electronics & $\mathrm{x}$ & - & - & - & - \\
\hline hexanal & $\begin{array}{l}\text { Floor skirting, pine floor strips, oak floor strips, laminate flooring, living-room rug, } \\
\text { vinyl flooring, plasterboard, particle board, sofa, wooden chair, magazines, newspaper }\end{array}$ & $\mathrm{x}$ & - & - & - & - \\
\hline 2,4-dimethyl-heptene & $\begin{array}{l}\text { Floor skirting, oak floor strips, laminate flooring, carpet material, carpet underlay, } \\
\text { living-room rug, vinyl flooring, curtains, plasterboard, particle board, sofa, mattress, } \\
\text { magazines, newspaper, computer fragments, clothing, electronics }\end{array}$ & $\mathrm{x}$ & - & - & - & - \\
\hline ethylbenzene & $\begin{array}{c}\text { Floor skirting, pine floor strips, oak floor strips, laminate flooring, carpet material, } \\
\text { living-room rug, vinyl flooring, curtains ( } 2 \text { ), plasterboard, sofa, wooden chair, } \\
\text { magazines, newspaper, computer fragments, electronics }\end{array}$ & $\mathrm{x}$ & $\mathrm{x}$ & - & $5.7 \times 10^{-2}$ & $8 \times 10^{-2}$ \\
\hline p-xylene & $\begin{array}{l}\text { Floor skirting, pine floor strips, oak floor strips, laminate flooring, carpet material, } \\
\text { living-room rug, vinyl flooring, curtains (2), plasterboard, sofa, wooden chair, mattress, } \\
\text { magazines, newspaper, electronics }\end{array}$ & $\mathrm{x}$ & $\mathrm{x}$ & - & $1.4 \times 10^{-1}$ & $4 \times 10^{-2}$ \\
\hline$o$-xylene & Vinyl flooring, curtains (2), electronics & $\mathrm{x}$ & $\mathrm{x}$ & - & $6.2 \times 10^{-2}$ & $2 \times 10^{-2}$ \\
\hline 2-heptanone & $\begin{array}{l}\text { Floor skirting, pine floor strips, laminate flooring, plaster board, particle board, sofa, } \\
\text { wooden chair, magazines, newspaper }\end{array}$ & $\mathrm{x}$ & - & - & $8 \times 10^{-3}$ & $9 \times 10^{-3}$ \\
\hline
\end{tabular}


Table 5. Cont

\begin{tabular}{|c|c|c|c|c|c|c|}
\hline \multirow[t]{2}{*}{ Compound } & \multirow[t]{2}{*}{ Substrates } & \multirow[t]{2}{*}{ White Spirit } & \multirow[t]{2}{*}{ Gasoline } & \multirow[t]{2}{*}{ Lamp Oil } & \multicolumn{2}{|c|}{$\begin{array}{l}\text { Frequency of Occurrences } \\
\text { [31] }\end{array}$} \\
\hline & & & & & IL & Substrate \\
\hline heptanal & $\begin{array}{l}\text { Floor skirting, pine floor strips, laminate flooring, plasterboard, particle board, sofa, } \\
\text { magazines, newspaper }\end{array}$ & $\mathrm{t}$ & $\mathrm{t}$ & - & - & - \\
\hline isopropylbenzene & Computer fragments, electronics & $\mathrm{x}$ & $\mathrm{x}$ & - & - & - \\
\hline 2-butoxy-ethanol & Sofa & $\mathrm{x}$ & $\mathrm{x}$ & - & $4.9 \times 10^{-2}$ & $5 \times 10^{-2}$ \\
\hline propylbenzene & Carpet material, magazines, electronics & $\mathrm{x}$ & $\mathrm{x}$ & - & - & - \\
\hline 3-chloromethyl-heptane & Electronics & $\mathrm{x}$ & - & - & - & - \\
\hline 1,2,4-trimethylbenzene & Floor skirting, pine floor strips, oak floor strips, carpet underlay & $\mathrm{x}$ & $\mathrm{x}$ & - & $1.84 \times 10^{-1}$ & $9 \times 10^{-3}$ \\
\hline furfural & $\begin{array}{l}\text { Pine floor strips, oak floor strips, laminate flooring, plasterboard, sofa, magazines, } \\
\text { newspaper, Clothing }\end{array}$ & $\mathrm{x}$ & - & - & - & - \\
\hline$o / p$-cymene & Particle board & $\mathrm{x}$ & $\mathrm{t}$ & - & - & - \\
\hline limonene & Pine floor strips, plasterboard, particle board, sofa, mattress, clothing & $\mathrm{x}$ & - & - & $5.7 \times 10^{-2}$ & $6 \times 10^{-2}$ \\
\hline dietyl phthalate & Mattress, clothing, electronics & $\mathrm{t}$ & $\mathrm{t}$ & $\mathrm{t}$ & - & - \\
\hline diisobutyl phthalate & Sofa, mattress, clothing, electronics & $\mathrm{t}$ & $\mathrm{t}$ & $\mathrm{t}$ & - & - \\
\hline n-octane & Particle board, wooden chair & $\mathrm{x}$ & $\mathrm{x}$ & $\mathrm{x}$ & - & - \\
\hline n-nonane & $\begin{array}{l}\text { Floor skirting, pine floor strips, carpet underlay, particle board, magazines, clothing, } \\
\text { electronics }\end{array}$ & $\mathrm{x}$ & $\mathrm{x}$ & $\mathrm{x}$ & $2.49 \times 10^{-1}$ & $9 \times 10^{-3}$ \\
\hline n-decane & $\begin{array}{l}\text { Floor skirting, pine floor strips, oak floor strips, laminate flooring, vinyl flooring, } \\
\text { curtains (1), plasterboard, sofa, mattress, magazines, newspaper, clothing, electronics }\end{array}$ & $\mathrm{x}$ & $\mathrm{t}$ & $\mathrm{x}$ & $3 \times 10^{-2}$ & $2 \times 10^{-2}$ \\
\hline$n$-undecane & $\begin{array}{l}\text { Floor skirting, pine floor strips, oak floor strips, laminate flooring, vinyl flooring, } \\
\text { curtains, plasterboard, sofa, mattress, magazines, newspaper, clothing, electronics }\end{array}$ & $\mathrm{x}$ & $\mathrm{t}$ & $\mathrm{x}$ & $3.2 \times 10^{-1}$ & $3 \times 10^{-2}$ \\
\hline n-dodecane & $\begin{array}{l}\text { Floor skirting, oak floor strips, laminate flooring, vinyl flooring, curtains, plasterboard, } \\
\text { sofa, mattress, magazines, newspaper, clothing, electronics }\end{array}$ & $\mathrm{x}$ & $\mathrm{t}$ & $\mathrm{x}$ & $2.36 \times 10^{-1}$ & $2 \times 10^{-2}$ \\
\hline$n$-tridecane & $\begin{array}{l}\text { Floor skirting, oak floor strips, laminate flooring, vinyl flooring, curtains, plasterboard, } \\
\text { sofa, mattress, magazines, newspaper, clothing, electronics }\end{array}$ & $\mathrm{x}$ & $\mathrm{t}$ & $\mathrm{x}$ & $1.59 \times 10^{-1}$ & $2 \times 10^{-2}$ \\
\hline$n$-tetradecane & $\begin{array}{l}\text { Floor skirting, oak floor strips, laminate flooring, vinyl flooring, curtains, plasterboard, } \\
\text { sofa, mattress, magazines, newspaper, clothing, electronics }\end{array}$ & $\mathrm{x}$ & $\mathrm{t}$ & $\mathrm{x}$ & $1.4 \times 10^{-1}$ & $9 \times 10^{-3}$ \\
\hline
\end{tabular}


This table also includes the corresponding frequency of occurrences as reported from Table 2 of the article of the Sigman group [31]. For this selection of compounds a high degree of consistency was observed between our data and the data collected by the University of Central Florida (UCF). From the 36 compounds mentioned in Table 2 of a previous paper [31], at least 14 were also found in our study. Four of the 36, i.e., alpha-pinene, beta-pinene, camphor, and alpha terpineol, are listed as major compounds in both burned substrates and ILs. However, we did not identify these compounds in the intact ILs because the current study only includes three types of IL (gasoline, white spirit, and lamp oil), whereas the work of the Sigman group [31] includes major compounds found in the ILRC database representing all ASTM E1618-14 classes. The remaining entries in Table 2 of a past paper [31] were not identified in the headspace of the substrate fire experiments in this study. These compounds could be present at trace level in the headspace extracts but it should also be noted that for these compounds a limited number of occurrences were reported (except for naphthalene found in $15 \%$ of the substrate samples in the UCF database).

By combining the results from the intact IL analysis (3.2) with the characterization of the substrate burn headspace, a list of potential markers can be extracted that are exclusively found in intact ILs. The presence of these compounds in the headspace of fire debris (as discussed in Section 3.4) can therefore be a strong indicator of the presence of IL residue with a very low false positive rate (it should be noted that this only applies to major constituents as trace level presence in the headspace of burnt substrate cannot be excluded). From Table S2 of the Supplementary Information these 'IL exclusive' compounds were filtered resulting in Table 6. Branched alkanes were excluded from this list, since these compounds are hard to unambiguously identify due to isomer complexity making it difficult to verify their absence in substrate fire debris headspace.

Table 6. Major compounds ' $x$ ' identified only in ILs and not encountered in the headspace of burnt substrates. Some components are identified as a minor constituent ' $\mathrm{m}$ ' in the IL and sometimes it varies from sample-to-sample ' $\mathrm{x} / \mathrm{m}$ '.

\begin{tabular}{lccc}
\hline \multicolumn{1}{c}{ Compounds } & White Spirit & Gasoline & Lamp Oil \\
\hline Alkanes & & & \\
\hline$n$-Alkanes & & & \\
Pentadecane & - & $\mathrm{m}$ & $\mathrm{x} / \mathrm{m}$ \\
Hexadecane & - & $\mathrm{m}$ & $\mathrm{x} / \mathrm{m}$ \\
Heptadecane & - & - & $\mathrm{x} / \mathrm{m}$ \\
Octadecane & - & - & $\mathrm{x} / \mathrm{m}$ \\
nonadecane & - & - & $\mathrm{x} / \mathrm{m}$ \\
icosane & & & $\mathrm{x} / \mathrm{m}$ \\
\hline Cyclo-alkanes & $\mathrm{x}$ & $\mathrm{x}$ & \\
methylcyclohexane & - & $\mathrm{x}$ & $\mathrm{x} / \mathrm{m}$ \\
ethylcyclohexane & $\mathrm{x}$ & - & - \\
butylcyclohexane & $\mathrm{x}$ & - & - \\
pentylcyclohexane & & & \\
\hline Aromatics & & & \\
\hline$C_{3}$-alkylbenzenes & $\mathrm{x}$ & $\mathrm{x}$ & - \\
3-ethyltoluene & $\mathrm{x}$ & $\mathrm{x}$ & - \\
4-ethyltoluene & $\mathrm{x}$ & $\mathrm{x}$ & - \\
1,3,5-trimethylbenzene & $\mathrm{x}$ & $\mathrm{x}$ & - \\
2-ethyltoluene & $\mathrm{x}$ & $\mathrm{x}$ & - \\
1,2,3-trimethylbenzene & & $\mathrm{x}$ & - \\
\hline C -alkylbenzene 1 & $\mathrm{x}$ & $\mathrm{x} / \mathrm{m}$ & - \\
1-methylpropylbenzene & & $\mathrm{x} / \mathrm{m}$ & - \\
1,3-diethylbenzene & & & \\
1,4-diethylbenzene & 1-methyl-3-propylbenzene & & \\
\hline
\end{tabular}


Table 6. Cont.

\begin{tabular}{lccc}
\hline \multicolumn{1}{c}{ Compounds } & White Spirit & Gasoline & Lamp Oil \\
\hline 1-methyl-4-propylbenzene & $\mathrm{x}$ & $\mathrm{x} / \mathrm{m}$ & - \\
2-ethyl-1,4-dimethylbenzene & $\mathrm{x}$ & $\mathrm{x} / \mathrm{m}$ & - \\
1,2,3,4-tetramethylbenzene & $\mathrm{x}$ & $\mathrm{x} / \mathrm{m}$ & - \\
1,2,4,5-tetramethylbenzene & $\mathrm{x}$ & $\mathrm{x} / \mathrm{m}$ & - \\
\hline Naphthalenes & & & \\
naphthalene & $\mathrm{x}$ & $\mathrm{x}$ & - \\
1,3-dimethylnaphthalene & - & $\mathrm{x}$ & - \\
2,3-dimethylnaphthalene & - & $\mathrm{x}$ & - \\
1-methylnaphthalene & $\mathrm{m}$ & $\mathrm{x} / \mathrm{m}$ & - \\
2-methylnaphthalene & $\mathrm{m}$ & $\mathrm{x} / \mathrm{m}$ & - \\
1,2,3,4-tetrahydronaphthalene & $\mathrm{x}$ & - & - \\
\hline Indane & $\mathrm{x}$ & - \\
\hline indane & \multicolumn{1}{c}{}
\end{tabular}

\subsection{Fire Experiments with IL: Ignitable Liquid Detection and Classification in Fire Debris}

The experimental design developed for this study included 45 substrate mixtures. These were prepared twice for comparison with and without the addition of ignitable liquids.

In Figure 8 typical GC $\times$ GC-TOFMS chromatograms are shown for the burn experiments for each of the IL classes used. Figure $8 \mathrm{~A}$ resulted from experiment 69 , which had the same substrates as experiment 24 (see Figure 7), i.e., carpet material as primary substrate and oak floor strips, carpet underlay, computer fragments, and electronics as secondary substrates, with the addition of white spirit (Gamma, see Table 2 for details). It should be noted that both figures are scaled differently, the overall GC $\times$ GC-TOFMS signal is orders of magnitude higher for the headspace extract of the burn experiment with white spirit. Figure $8 \mathrm{~B}$ resulted from experiment 83 , with laminate flooring as primary substrate and sofa, clothing, mattress, and electronics as secondary substrate. In this experiment gasoline (Texaco Unleaded 95) was added as the IL. Figure 8 C resulted from experiment 105, with sofa as primary substrate and carpet underlay, mattress, magazines, and carpet material as secondary substrates. To this substrate mixture lamp oil (Kruidvat) was added prior to the burn experiment.

Figure S6 includes all chromatograms of the substrate mixtures with IL. These results illustrate the extensive variety in terms of headspace amount and composition in line with the uncontrolled nature of a fire (even if performed under controlled laboratory conditions).

In Section 3.3 the chemical composition of the substrate related headspace was elaborated including compounds that can potentially lead to a false positive outcome (identifying an IL when actually none was present). By focusing only on the compounds that are present in the three classes of ILs but are not found in significant amounts in the headspace of any of the substrate and substrate mixture burns (as listed in Table 6) a very straight forward approach for IL identification and classification can be applied [34]. If any of these compounds are found in the headspace of a burn experiment the presence of IL residue in the fire debris is confirmed. The results of this simple approach are depicted in Table 7 together with the results of Lopatka et al. [22] who applied complex data analysis based on local summed ion spectra (LIS) to the same data set.

The occurrence of a false positive rate of $7 \%$ can be explained by the somewhat subjective distinction between major and minor compounds specifically for the alkanes of low volatility which are indicators for the presence of lamp oil. In comparison with the LIS approach in a previous paper [22] the use of 'IL exclusive compounds' leads to a higher false positive but also to a higher true positive rate. However, important to note is that no cross-validation was applied in this particular study, contrary to the work of Lopatka et al. [22]. Hence, the higher false positive rates reported previously [22] are the outcome from cross-validation, whereas in the current research the false positive 
rates are the result of the subjective nature of the decision model. In this respect, the work presented by Lopatka et al. [22] can be considered as a much more scientific robust analysis of the same data set. Validating the presented approach would require the GC $\times$ GC-TOFMS analysis of a large collection of casework samples to test the hypotheses that form the basis for detection and classification which was beyond the scope of this work.
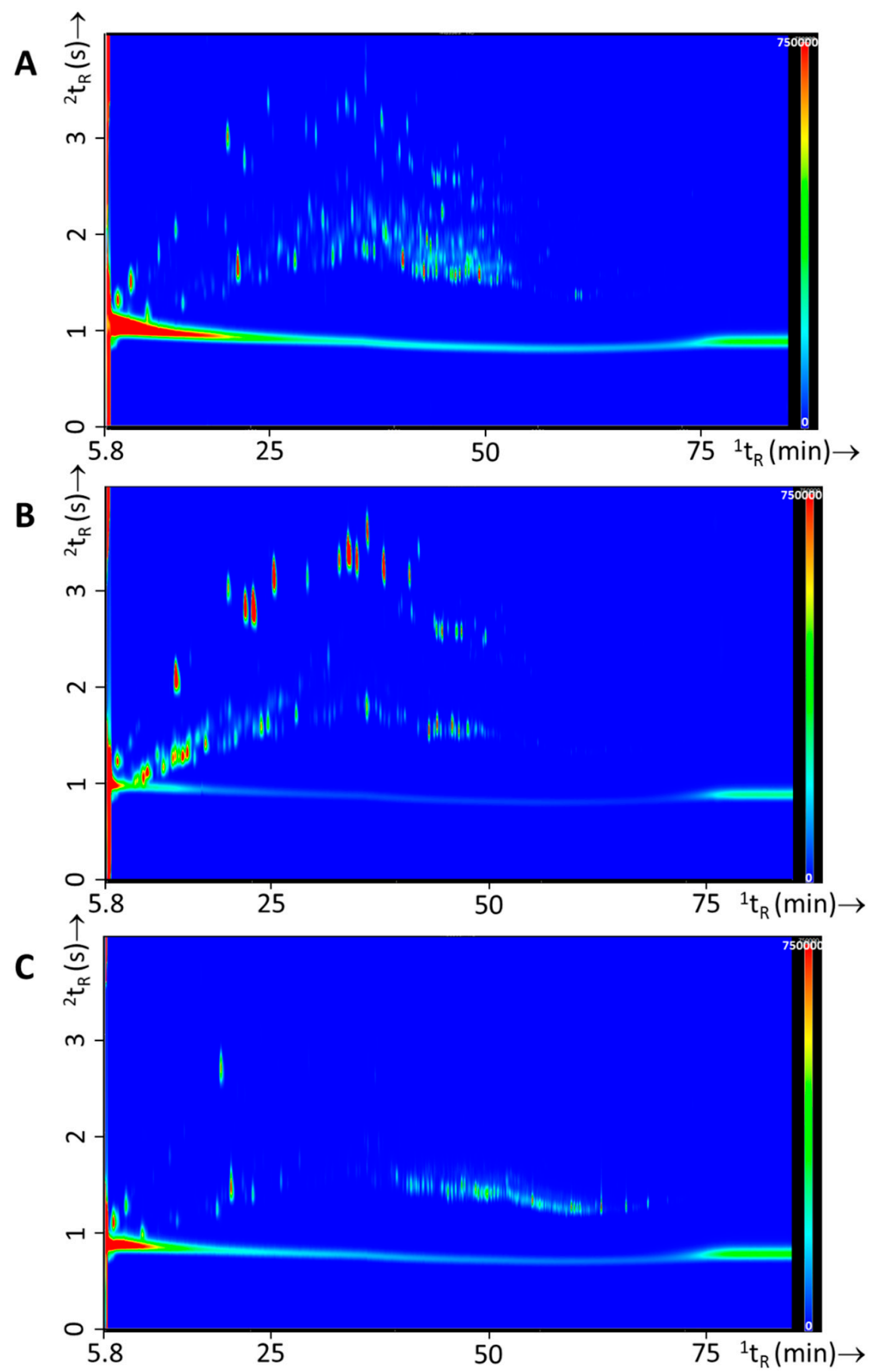

Figure 8. Typical GC $\times$ GC-TOFMS TIC contour plots for fire debris experiments with IL, with (A) experiment 69-white spirit, (B) experiment 83-gasoline, and (C) experiment 105-lamp oil. 
Table 7. Detection of ILs in fire debris samples with the true and false positives and negatives for this study and as reported previously [22] for the same data set $(n=90,45$ substrate mixture burns without IL and 45 substrate mixture burns with IL).

\begin{tabular}{cccccccc}
\hline \multicolumn{2}{c}{ This Study } & \multicolumn{2}{c}{ Analysis } & \multicolumn{2}{c}{ Lopatka et al. } & \multicolumn{2}{c}{ Analysis } \\
\hline & ILR (-) & ILR (+) & & & ILR (-) & ILR (+) \\
\hline \multirow{2}{*}{ TRUE } & ILR (-) & $93 \%$ & $7 \%$ & \multirow{2}{*}{ TRUE } & ILR (-) & $99 \%$ & $1 \%$ \\
& ILR (+) & $11 \%$ & $89 \%$ & & ILR (+) & $39 \%$ & $61 \%$ \\
\hline
\end{tabular}

Overall, Table 7 illustrates that the enhanced peak capacity offered by GC $\times$ GC [27] turns out to be beneficial for the data analysis approach based on marker compound detection in current study and can lead to promising results.

With Table 6 the presence of an IL was determined. This list was also used to create a heuristic model in the form of a decision tree (See Figure 9) to determine the class of IL for the samples in which an IL marker compound was detected in the headspace. Unique combinations of compounds were considered that would exclude the other classes of ILs. As an example, major aromatic compounds listed in Table 6 were not found in the intact lamp oils. Therefore, fire debris samples, in which these specific constituents were not observed, indicated the presence of lamp oil. The decision tree is binary in nature only considering the presence or absence of an IL classifier compound. This makes data interpretation easy but does not consider trace levels of compounds of interest and results in a somewhat subjective decision based on peak area and quality of the mass spectrum used for identification.

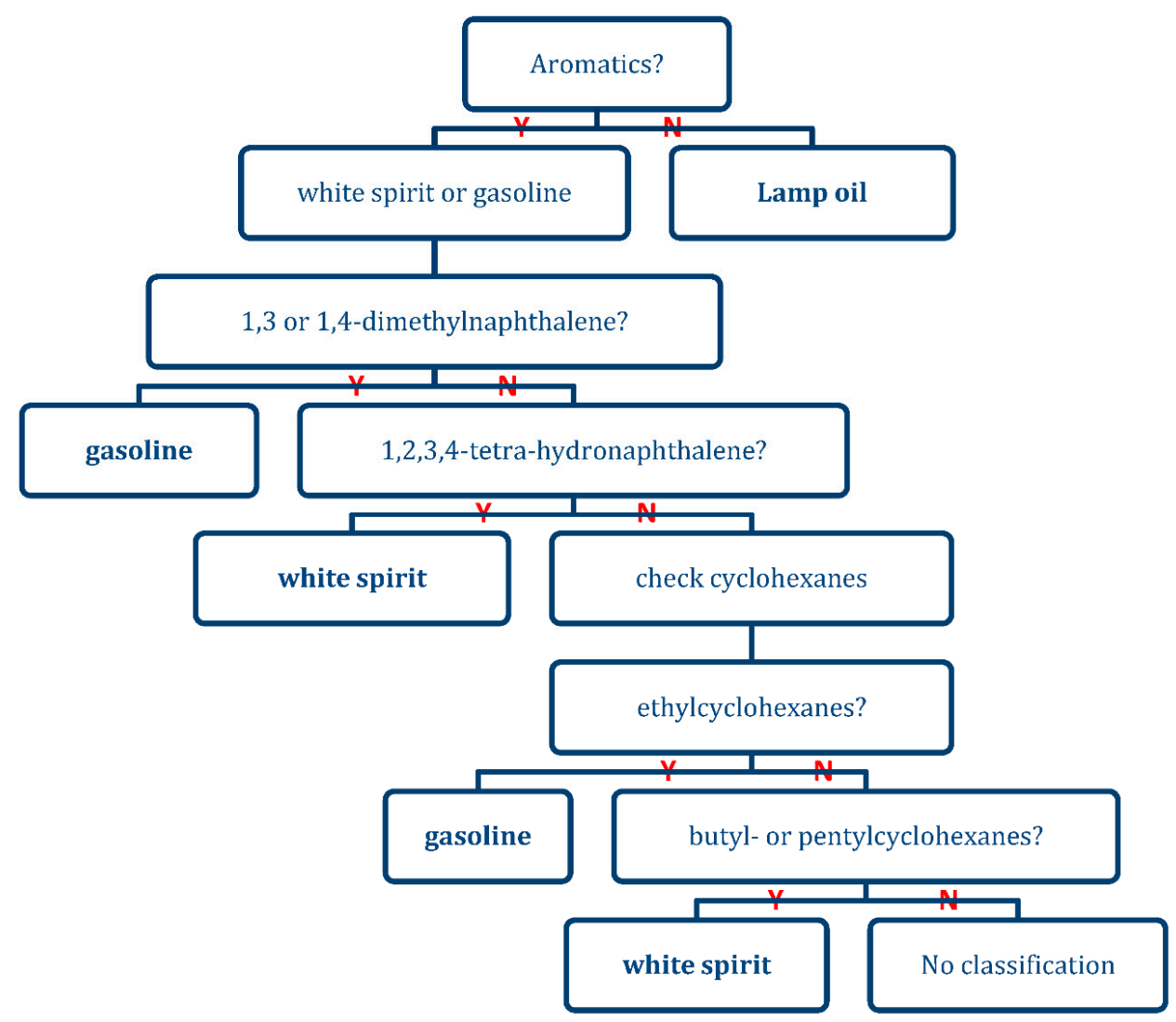

Figure 9. A heuristic model created from Table 6. 
With the heuristic model presented in Figure 9 based on the marker compounds in Table 6, all chromatograms with a positive result on the presence of an IL were re-analyzed for IL classification. The corresponding results can be found in Table 8 .

Table 8. IL classification for burn experiments $(n=85,40$ burn experiments in which IL was detected and 45 burn experiments without IL).

\begin{tabular}{ccccccc}
\hline & & \multicolumn{5}{c}{ Analysis } \\
\cline { 3 - 6 } & & White Spirit & Gasoline & Lamp Oil & ILR (-) & Not Identified \\
\hline \multirow{3}{*}{ TRUE } & White Spirit & $100 \%$ & $0 \%$ & $0 \%$ & $0 \%$ & $0 \%$ \\
& Gasoline & $0 \%$ & $79 \%$ & $0 \%$ & $0 \%$ & $21 \%$ \\
& Lamp oil & $0 \%$ & $15 \%$ & $77 \%$ & $0 \%$ & $8 \%$ \\
& ILR (-) & $0 \%$ & $0 \%$ & $5 \%$ & $93 \%$ & $2 \%$ \\
\hline
\end{tabular}

With the applied method we correctly identified the presence of white spirit for all burns in which this IL was actually used. Compared to the results from the Lopatka study [22], gasoline identification was less successful but a higher correct classification rate was obtained for lamp oil. However, no cross-validation was applied in the current study and direct comparison is therefore not possible. It should be noted that the very basic decision tree methodology also resulted in a significant number of indecisive results with respect to gasoline and lamp oil. For lamp oil, this was caused by the presence of an aromatic target compound at a significant level (e.g., from the substrate) in the absence of the correct white spirit and gasoline markers. For gasoline, this is caused by the volatility and low intrinsic levels of the marker compounds which resulted in a few burn experiments in which these markers were not observed in the headspace extracts. Overall the results illustrate that also satisfactory correct classification rates can be obtained by applying simple chemistry-based decision rules to comprehensive GC $\times$ GC-TOFMS datasets. Such an approach may be less straight forward when considering GC-MS data.

From a practical point of view a simple model as presented makes it manageable to deal with complex GC $\times$ GC data. However, the major drawback of this binary methodology-in which some subjective interpretation is involved-is the difficulty in reporting on probabilities of evidence given a certain hypothesis. For actual casework the latter is crucial. Therefore, the likelihood ratio approach [22] is the more justified and recommended methodology.

In the last part of this study the possibility of differentiating between various brands of gasoline in fire debris samples was explored. As a best case scenario the two gasoline samples which could clearly be distinguished as intact liquids (see Figure 6) were selected. From Figure 6 it was already shown that these samples could be differentiated based on the presence of the naphthalenes and different ratios of the $\mathrm{C}_{3}$ - and $\mathrm{C}_{4}$-alkylbenzenes. In Figure 10 the GC $\times$ GC-TOFMS chromatograms are depicted from the fire debris sample in which these gasolines were applied as IL (experiments 82 and 84).

On the basis of the data shown in Figure 10, differentiation between the two gasolines was not possible. More in-depth analysis of the comprehensive data sets did not reveal the typical naphthalene profiles [7,32] which could be used to distinguish these two gasoline samples. It should be noted that for these two particular experiments the fire was extensive leading to a reduced amount of compounds in the headspace. So potentially within-class differentiation is still feasible in those cases where unconsumed IL is still present in the fire debris. However, in actual casework, fires are uncontrolled and the fire conditions are often unknown. Under these circumstances we feel that comparing an IL residue to an intact IL (e.g., as found at the home of a suspect) will remain extremely challenging even when using GC $\times$ GC-TOFMS. 


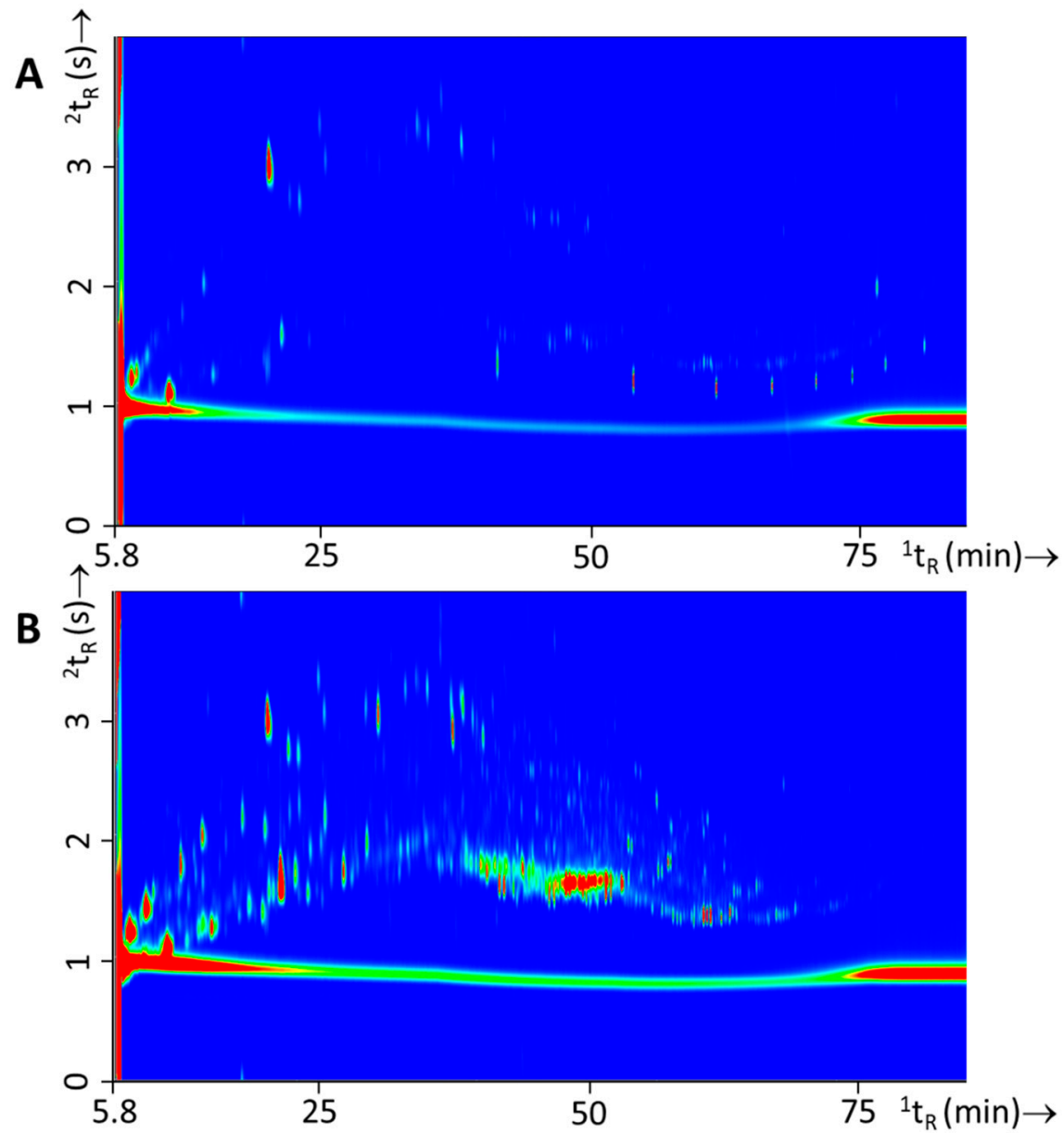

Figure 10. GC $\times$ GC-TOFMS TIC contour plot of (A) experiment 82 and (B) experiment 84 .

\section{Conclusions}

Fire debris analysis is a complex and challenging task due to several interfering factors influencing the interpretation. The use of simulated fire debris samples might give a better understanding and improve the methodology for the detection and identification of ILRs in fire debris samples. In this study, an experimental design has been presented for laboratory-scale controlled fire experiments under realistic burn conditions in combination with chemical analysis using advanced separation and detection techniques. The advantage of the enhanced peak capacity offered by GC $\times$ GC was used for a data analysis approach based on target compound detection.

GC $\times$ GC-TOFMS headspace analysis of the substrates resulted in an overview of substrate specific compounds. Combining these results with the analysis of intact ILs resulted in an 'IL exclusive' target compound list which was used for the identification of ILs in fire debris samples. For classification, a simple heuristic model, in the form of a decision tree, was developed based on the IL specific compounds. Promising results were obtained with this methodology for the detection and classification of ILRs in fire debris samples. Although we succeeded in the identification and classification of ILs in fire debris samples, it was not possible to differentiate between the same class of IL in fire debris samples.

This study clearly shows the potential of GC $\times$ GC-TOFMS for forensic fire debris analysis, however it should be noted our findings are based on a limited set of fire experiments $(n=110)$ under controlled laboratory conditions including only three IL classes (gasoline, white spirit, and lamp oil).

The experimental design, in combination with advanced chromatographic techniques and the target compound detection approach, could serve as a valuable starting point for future work on 
GC $\times$ GC-TOFMS with algorithmic classification. The heuristic model is currently limited by its subjective nature and difficulties in reporting on values of evidence. Also, the limited number of experiments, substrates, and ILs form a drawback and this model can therefore not be considered representative of expected casework. In real case scenarios the forensic experts must consider the entire spectrum of ILs and are faced with fire debris samples without any knowledge of the substrates involved.

Supplementary Materials: The following are available online at http:/ /www.mdpi.com/2297-8739/5/3/43/s1 and https://zenodo.org/record/1405220\#.W4YB11KSCJ0, Figure S1: IL_white spirit, Figure S2: IL_gasoline, Figure S3: IL_Lamp oil, Figure S4: Single substrates, Figure S5: Substrate mixtures, Figure S6: Substrate mixtures with IL, Table S1: Details of ILs, Table S2: Typical compounds in ILs, Table S3: Compounds identified in substrates, Video S1: Fire experiment.

Author Contributions: Conceptualization, A.A.S.S., M.L., G.V.-T., M.S., P.J.S., and A.C.v.A.; Methodology, B.v.D. and A.A.S.S.; Experimental Design, M.L., G.V.-T., and M.S.; Investigation, B.v.D., M.L., and A.A.S.S.; Resources and Instrumentation, H.M. and G.v.d.W.; Data Analysis, A.A.S.S.; Writing-Original Draft Preparation, A.A.S.S.; Editing, A.A.S.S., A.C.v.A., and P.J.S.; Review, all authors; Visualization, A.A.S.S.; Supervision, A.C.v.A. and P.J.S.; Project Administration, A.A.S.S.; Funding Acquisition, G.V.-T., M.S., A.C.v.A., and P.J.S.

Funding: The COMFOR project is funded by The Netherlands Organization for Scientific Research (NWO) under Grant Number 727.011.006.

Acknowledgments: Our sincere thanks to Jos Lelieveld, Rabinder Gajadhar, and Folkert van Rijswijk of the BTM (technical fire investigation) team at the NFI for their support during the burn experiments. Rijk van den Dikkenberg of the IFV (Netherlands Institute of Safety) and his team are acknowledged for sharing their experience and giving us the opportunity to participate in their test burns. We are also grateful to Tom Aalbers and Peter Verschuren for their technical laboratory support at the University of Amsterdam, Anja Zwaneveld, Federico Muffatto, and Erik Metscher for their help during the sample preparation and Professor Hans-Gerd Janssen for his advice on method development and troubleshooting for GC $\times$ GC. Furthermore, we would like to express our gratitude to Michiel Grutters (Netherlands Forensic Institute) for reviewing the manuscript and Andrei Barcaru (University of Groningen) for his attempts in providing help with data analysis using a different approach. Finally, we thank the CIO (chemical identification) team of the NFI for their expert advice on fire debris analysis and their flexibility and support in providing opportunities for data analysis.

Conflicts of Interest: The authors declare no conflicts of interest.

\section{References}

1. Stauffer, E.; Dolan, J.A.; Newman, R. Fire Debris Analysis; Academic Press, Elsevier: London, UK, 2008; ISBN 9780126639711.

2. ASTM E1618-14. Standard Test Method for Ignitable Liquid Residues in Extracts from Fire Debris Samples by Gas Chromatography-Mass Spectrometry; ASTM International: West Conshohocken, PA, USA, 2014.

3. Sandercock, P.M.L. Fire investigation and ignitable liquid residue analysis-A review: 2001-2007. Forensic Sci. Int. 2008, 176, 93-110. [CrossRef] [PubMed]

4. Pert, A.D.; Baron, M.G.; Birkett, J.W. Review of Analytical Techniques for Arson Residues. J. Forensic Sci. 2006, 51, 1033-1049. [CrossRef] [PubMed]

5. Martín-Alberca, C.; Ortega-Ojeda, F.E.; García-Ruiz, C. Analytical tools for the analysis of fire debris. A review: 2008-2015. Anal. Chim. Acta 2016, 928, 1-19. [CrossRef] [PubMed]

6. Sampat, A.A.S.; Lopatka, M.; Vivó-Truyols, G.; Schoenmakers, P.J.; van Asten, A.C. Towards chemical profiling of ignitable liquids with comprehensive two-dimensional gas chromatography: Exploring forensic application to neat white spirits. Forensic Sci. Int. 2016, 267, 183-195. [CrossRef] [PubMed]

7. Sandercock, P.M.L.; Du Pasquier, E. Chemical fingerprinting of unevaporated automotive gasoline samples. Forensic Sci. Int. 2003, 134, 1-10. [CrossRef]

8. Frysinger, G.S.; Gaines, R.B. Forensic analysis of ignitable liquids in fire debris by comprehensive two-dimensional gas chromatography. J. Forensic Sci. 2002, 47, 471-482. [CrossRef] [PubMed]

9. Peschier, L.J.C.; Grutters, M.M.P.; Hendrikse, J.N. Using Alkylate Components for Classifying Gasoline in Fire Debris Samples. J. Forensic Sci. 2018, 63, 420-430. [CrossRef] [PubMed]

10. Baerncopf, J.; Hutches, K. A review of modern challenges in fire debris analysis. Forensic Sci. Int. 2014, 244, e12-e20. [CrossRef] [PubMed] 
11. Hendrikse, J. ENFSI collaborative testing programme for ignitable liquid analysis: A review. Forensic Sci. Int. 2007, 167, 213-219. [CrossRef] [PubMed]

12. Prather, K.R.; McGuffin, V.L.; Waddell, S.R. Effect of evaporation and matrix interferences on the association of simulated ignitable liquid residues to the corresponding liquid standard. Forensic Sci. Int. 2012, 222, 242-251. [CrossRef] [PubMed]

13. Hendrikse, J.; Grutters, M.; Schäfer, F. Identifying Ignitable Liquids in Fire Debris; Academic Press, Elsevier: London, UK, 2016; ISBN 9780128043165.

14. Fernandes, M.S.; Lau, C.M.; Wong, W.C. The effect of volatile residues in burnt household items on the detection of fire accelerants. Sci. Justice 2002, 42, 7-15. [CrossRef]

15. Li, Y.Y.; Liang, D.; Shen, H. An analysis of background interference on fire debris. Procedia Eng. 2013, 52, 664-670. [CrossRef]

16. Borusiewicz, R.; Zieba-Palus, J.; Zadora, G. The influence of the type of accelerant, type of burned material, time of burning and availability of air on the possibility of detection of accelerants traces. Forensic Sci. Int. 2006, 160, 115-126. [CrossRef] [PubMed]

17. Almirall, J.R.; Furton, K.G. Characterization of background and pyrolysis products that may interfere with the forensic analysis of fire debris. J. Anal. Appl. Pyrolysis 2004, 71, 51-67. [CrossRef]

18. Americal Society for Testing Materials. ASTM E 1412-00 Standard practice for separation of ignitable liquid residues from fire debris samples by passive headspace concentration with activated charcoal. In Annual Book of ASTM Standards; ASTM International: West Conshohocken, PA, USA, 2001; pp. 431-433.

19. Lennard, C.J.; Tristan Rochaix, V.; Margot, P.; Huber, K. A GC-MS database of target compound chromatograms for the identification of arson accelerants. Sci. Justice 1995, 35, 19-30. [CrossRef]

20. Schwartz, Z.; An, Y.; Konstantynova, K.I.; Jackson, G.P. Analysis of household ignitable liquids and their post-combustion weathered residues using compound-specific gas chromatography-combustion-isotope ratio mass spectrometry. Forensic Sci. Int. 2013, 233, 365-373. [CrossRef] [PubMed]

21. Choi, S.; Yoh, J.J. Fire debris analysis for forensic fire investigation using laser induced breakdown spectroscopy. Spectrochim. Acta Part B At. Spectrosc. 2017, 134, 75-80. [CrossRef]

22. Lopatka, M.; Sampat, A.A.; Jonkers, S.; Adutwum, L.A.; Mol, H.G.J.; van der Weg, G.; Harynuk, J.J.; Schoenmakers, P.J.; van Asten, A.; Sjerps, M.J.; et al. Local Ion Signatures (LIS) for the examination of comprehensive two-dimensional gas chromatography applied to fire debris analysis. Forensic Chem. 2017, 3, 1-13. [CrossRef]

23. Gruber, B.; Weggler, B.A.; Jaramillo, R.; Murrell, K.A.; Piotrowski, P.K.; Dorman, F.L. Comprehensive two-dimensional gas chromatography in forensic science: A critical review of recent trends. TrAC Trends Anal. Chem. 2018, 105, 292-301. [CrossRef]

24. Sampat, A.; Lopatka, M.; Sjerps, M.; Vivo-Truyols, G.; Schoenmakers, P.; van Asten, A. Forensic potential of comprehensive two-dimensional gas chromatography. TrAC Trends Anal. Chem. 2016, 80, 345-363. [CrossRef]

25. Taylor, C.M. An Arson Investigation by using Comprehensive Two-dimensional Gas ChromatographyQuadrupole Mass Spectrometry. J. Forensic Res. 2012, 3. [CrossRef]

26. Jonkers, S. Local Ion Signatures (LIS) for Forensic Comparison of GCxGC-MS Data; University of Amsterdam: Amsterdam, The Netherlands, 2016.

27. Nizio, K.; Cochran, J.; Forbes, S. Achieving a Near-Theoretical Maximum in Peak Capacity Gain for the Forensic Analysis of Ignitable Liquids Using GC $\times$ GC-TOFMS. Separations 2016, 3, 26. [CrossRef]

28. Organtini, K.L.; Myers, A.L.; Jobst, K.J.; Cochran, J.; Ross, B.; McCarry, B.; Reiner, E.J.; Dorman, F.L. Comprehensive characterization of the halogenated dibenzo-p-dioxin and dibenzofuran contents of residential fire debris using comprehensive two-dimensional gas chromatography coupled to time of flight mass spectrometry. J. Chromatogr. A 2014, 1369, 138-146. [CrossRef] [PubMed]

29. Centraal Bureau voor Statistiek. Brandweerstatistiek 2013-2017; CBS: Den Haag, The Netherlands, $2013-2017$.

30. Mondello, L. Fundamental Principles of Comprehensive 2D GC. In GC $\times$ GC Handbook; Shimadzu Corporation: Kyoto, Japan, 2012; pp. 1-29.

31. Akmeemana, A.; Williams, M.R.; Sigman, M.E. Major chemical compounds in the Ignitable Liquids Reference Collection and Substrate databases. Forensic Chem. 2017, 5, 91-108. [CrossRef]

32. Sandercock, P.M.L.; Du Pasquier, E. Chemical fingerprinting of gasoline: 2. Comparison of unevaporated and evaporated automotive gasoline samples. Forensic Sci. Int. 2004, 140, 43-59. [CrossRef] [PubMed] 
33. Sinkov, N.A.; Harynuk, J.J. Cluster resolution: A metric for automated, objective and optimized feature selection in chemometric modeling. Talanta 2011, 83, 1079-1087. [CrossRef] [PubMed]

34. Adutwum, L.A.; Abel, R.J.; Harynuk, J. Total Ion Spectra versus Segmented Total Ion Spectra as Preprocessing Tools for Gas Chromatography-Mass Spectrometry Data. J. Forensic Sci. 2017, 63, 1059-1068. [CrossRef] [PubMed] 